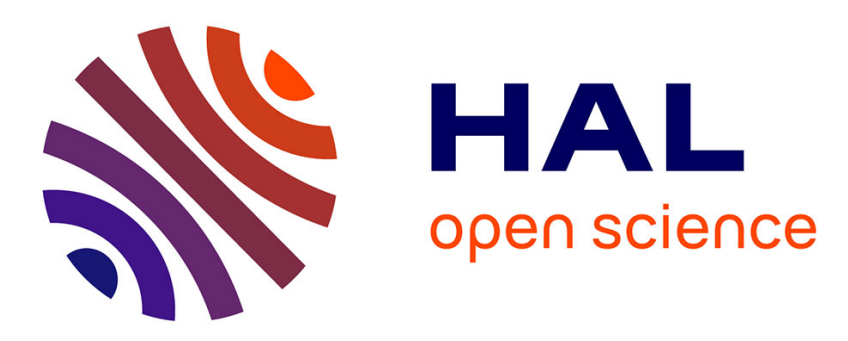

\title{
Double deuterated acetylacetone in neon matrices: infrared spectroscopy, photoreactivity and the tunneling process
}

Alejandro Gutiérrez Quintanilla, Michèle Chevalier, Claudine Crépin

\section{- To cite this version:}

Alejandro Gutiérrez Quintanilla, Michèle Chevalier, Claudine Crépin. Double deuterated acetylacetone in neon matrices: infrared spectroscopy, photoreactivity and the tunneling process. Physical Chemistry Chemical Physics, 2016, 18 (30), pp.20713 - 20725. 10.1039/c6cp02796b . hal-03097287

\section{HAL Id: hal-03097287 \\ https://hal.science/hal-03097287}

Submitted on 1 Feb 2021

HAL is a multi-disciplinary open access archive for the deposit and dissemination of scientific research documents, whether they are published or not. The documents may come from teaching and research institutions in France or abroad, or from public or private research centers.
L'archive ouverte pluridisciplinaire HAL, est destinée au dépôt et à la diffusion de documents scientifiques de niveau recherche, publiés ou non, émanant des établissements d'enseignement et de recherche français ou étrangers, des laboratoires publics ou privés. 


\title{
Double deuterated acetylacetone in neon matrices: infrared spectroscopy, photoreactivity and tunneling process
}

\author{
Alejandro Gutiérrez-Quintanilla ${ }^{\mathrm{a}, \mathrm{b}^{*}}$, Michèle Chevalier ${ }^{\mathrm{a}}$, and Claudine Crépin ${ }^{\mathrm{a}}$ \\ a Institut des Sciences Moléculaires d'Orsay (ISMO), UMR 8214, CNRS, Univ. Paris- Sud, Université \\ Paris-Saclay UMR 8214, F-91405 Orsay (France) \\ ${ }^{b}$ Instituto Superior de Tecnologías y Ciencias Aplicadas, La Habana (Cuba)
}

\begin{abstract}
The effect of deuteration of acetylacetone $\left(\mathrm{C}_{5} \mathrm{O}_{2} \mathrm{H}_{8}\right)$ is explored by means of IR spectroscopy of its single and double deuterated isotopologues trapped in neon matrices. The whole vibrational spectra of chelated enols are very sensitive to the H-D exchange of the hydrogen atom involved in the internal hydrogen bond. UV excitation of double deuterated acetylacetone isolated in neon matrices induces the formation of four open enol isomers which can be divided in two groups of two conformers, depending on their formation kinetics. Within each group, one conformer is more stable than the other: a slow conformer interconversion due to a tunneling process is observed in the dark at low temperature. Moreover, IR laser irradiation at the OD stretching overtone frequency is used to induce interconversion either from the most stable to the less stable conformer or the opposite, depending on the excitation wavelength. The interconversion process is of great help to assign conformers which are definitively identified by comparison between experimental and calculated IR spectra. Kinetic constants of the tunneling process at play are theoretically estimated and agree perfectly with experiments, including previous experiments with the totally hydrogenated acetylacetone [Lozada García et al. PCCP (2012) 14, 3450].
\end{abstract}

*Corresponding author: A. Gutiérrez-Quintanilla, e-mail: alejandro.gutierrez-quintanilla@u-psud.fr, address: ISMO, Bât.210, Université Paris Sud 11, 91405 Orsay Cedex France, tel.: +331691576 36, fax: +33169156777. 


\section{Introduction}

Acetylacetone $\left(\mathrm{C}_{5} \mathrm{H}_{8} \mathrm{O}_{2}\right)$ is the simplest molecule of the $\boldsymbol{B}$-diketones family. For many years, this compound has served as prototype in the investigations of three important physico-chemical processes: intramolecular proton transfer, ${ }^{1-4}$ keto-enolic tautomerism ${ }^{5-8}$ and photo-induced isomerization. ${ }^{9-14}$ Surprisingly very few studies are related with the effect of the exchange of an $\mathrm{H}$ atom by another ( $\mathrm{D}$ or $\mathrm{F}$ for example) $)^{1,3,4}$ although this change, deuteration in particular, could give information on the various physico-chemical properties of the molecule. The enolic form is stabilized by an internal hydrogen bond (Fig. 1) so only a small amount of the $B$-diketone form (keto) is present in the gas phase. ${ }^{5,15}$ The keto-enol tautomerism can be strongly affected by the environment ${ }^{16}$ but the prevailing form of the isolated molecule is chelated enol which symmetry has been a controversial topic: is it $C_{2 v}$ or $C_{s} ?^{17}$ Many experimental and theoretical works support the $C_{s}$ symmetry. ${ }^{8,18-20}$

Theoretically, eight stable enolic isomers are found: the chelated enol form - depicted in Fig. 1 - and seven open conformers ${ }^{*}{ }^{10,11,21}$ They are obtained by rotations around three bonds, two CC bonds and one $\mathrm{CO}$ bond as shown in Fig. 1, and are denoted $X Y Z$, where letters $X, Y$ and $Z$ stand for $\mathrm{C}$ or $\mathrm{T}$ depending on the cis or trans positions of the groups around the $\mathrm{C}-\mathrm{C}, \mathrm{C}=\mathrm{C}$ and $\mathrm{C}-\mathrm{O}$ bonds, respectively. The chelated enol (CCC) is the most stable form and the only one observed in the gas phase. In cryogenic matrices, it is also the most stable but several open conformers can be produced by UV irradiation. . $^{90,14,22,23}$

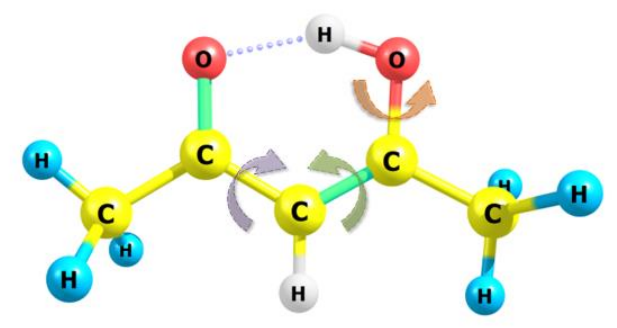

Figure 1: $\mathrm{CCC}$ enol conformer of acetylacetone. Hydrogen atoms exchanged with deuterium are marked in white. Each colored arrow defines one of the possible rotations in order to produce a new conformer.

The highly stabilizing hydrogen bond interaction in the CCC form prevents isomerization in the electronic ground state and an electronic excitation is required to access to the open forms. It has been suggested, from experiments and theoretical calculations, that this occurs through the excitation of the molecule to the $S_{2}$ level via a $\pi-\pi^{*}$ transition. Non-radiative processes like

\footnotetext{
* "conformer" is used here to refer to enolic rotational isomers
} 
internal conversion (IC) and intersystem crossing (ISC) between $S_{2} / S_{1} / T_{2} / T_{1}$ states lead the system to the $T_{1}$ state, where fragmentation (in gas phase) or isomerization (in cryogenic matrix) can occur. ${ }^{11,14,24-26}$

Photo-isomerization in matrices was probed in previous works by electronic and vibrational spectroscopy. Different kinds of matrices were used in order to test the influence of the environment in this photophysical process, among them: $\mathrm{N}_{2}, \mathrm{Ne}, \mathrm{Ar}, \mathrm{Xe}$ and hydrogen hosts (normal hydrogen $n-\mathrm{H}_{2}$, normal deuterium $n$ - $\mathrm{D}_{2}$ and para-hydrogen $p-\mathrm{H}_{2}$ ). ${ }^{9,10,12,14,23}$ The stabilization of different open conformers depends on the host. Previous studies in our group showed that in Ne and $p-\mathrm{H}_{2}$ matrices, only the CTC, TCC and TTC conformers, in which the $\mathrm{OH}$ group is in the cis conformation, were observed after $266 \mathrm{~nm}$ laser irradiation. ${ }^{14} \ln n-\mathrm{H}_{2}$ and $n$ $\mathrm{D}_{2}$, TCT (OH in trans conformation) was also detected. This conformer was also observed in $\mathrm{Ar}$, Xe and $\mathrm{N}_{2}$ matrices. ${ }^{10,12}$ Furthermore, CTT was stabilized in $\mathrm{N}_{2}$ and Xe. ${ }^{12,23}$ Consequently, it was proposed that CTT and TCT conformers were not observed in $p-\mathrm{H}_{2}$ and Ne because of a fast tunneling process of the hydrogen in the $\mathrm{OH}$ group converting CTT and TCT into CTC and TCC respectively. ${ }^{14}$

It is known from previous studies on small organic compounds (including acetylacetone) that interchange between two rotational conformers could be induced by irradiation with infrared laser matching its wavelength to the absorption of corresponding bond in the molecule. ${ }^{23,27,28} \mathrm{IR}$ irradiation did not affect the CCC conformer but selective IR irradiation on the $\mathrm{OH}$ stretching fundamentals induced changes in the CTC/CTT and TCC/TCT pairs of conformers. ${ }^{12}$ The interconversion was matrix dependent: not observed in $\mathrm{Ne}$ and $\mathrm{Ar}$ matrices, observed only in the CTC/CTT pair in Xe and observed in both pairs in $\mathrm{N}_{2}$.

The present paper is focused on the role played by the hydrogen atom from the $\mathrm{OH}$ group in the stabilization of non-chelated enolic conformers, with an experimental approach. For this purpose, we study double deuterated acetylacetone, an isotopologue of the original fully hydrogenated molecule. The structural picture of acetylacetone in its chelated enol form is presented in Fig 1. As it can be seen this molecule has two $\mathrm{CH}_{3}$ groups and hydrogens in $\mathrm{OH}$ and $\mathrm{CH}$ groups. It is known that $\mathrm{OH}$ and $\mathrm{CH}$ hydrogens are much more labile and could be easily exchanged with deuterons in the presence of e.g. $\mathrm{D}_{2} \mathrm{O}$. The double deuteration concerns these most labile hydrogen atoms, labeled in white color in Fig. 1 . In this study we present investigation of the deuteration influence to the vibrational spectra as well as to the structure and stability of the isomers. The double deuterated acetylacetone has been previously studied in pure solid, liquid and gas phases through FT-IR spectroscopy. ${ }^{29-32}$ All these works report 
studies on the chelated enol form (CCC), and none of them on the open enol conformers. In the present work, UV and IR induced isomerization is investigated in solid neon using FT-IR spectroscopy for detailed characterization of possible isomers. Infrared absorption bands are assigned to the particular conformer based on the calculated spectra of the conformers. After the presentation of the experimental and theoretical methods used in the study (part II), the results are described and discussed in part III. Geometries, energetic and vibrational frequencies from calculations are briefly described. The deuterated isotopologues, including double and mono deuterated acetylacetone, in freshly deposited samples are then characterized. UV absorption spectra of conformers of acetylacetone isolated in neon matrices are also reported. Photo-isomerization induced by UV or IR laser irradiation is described and analyzed. Various conformers are obtained. Some of them are metastable in the matrix, as shown by the timeevolution of their bands without any irradiation. The vibrational structure of five conformers of double deuterated acetylacetone (XYZ=CCC, CTC, CTT, TCC and TCT) is thus clearly documented as well as the interconversion between them. The tunneling process at play in the interconversion is discussed at the end of part III. Part IV summarizes the main conclusions of the work.

The following notations will be used: $A c A c H 8, A c A c D 2$ and $A c A c D 1$ to name fully hydrogenated, double deuterated and monodeuterated acetylacetone, respectively. There are two AcAcD1, distinguished by the notations $A c A c D 1(C D)$ and $A c A c D 1(O D)$, depending on the position of deuterium atom. Specific conformers of the corresponding species will be noted $\mathrm{XYZ}(\mathrm{H} 8)$, $\mathrm{XYZ}(\mathrm{D} 2), \mathrm{XYZ}(\mathrm{D} 1)$ (or $\mathrm{XYZ}(\mathrm{CD})$ and $\mathrm{XYZ}(\mathrm{OD})$ ) with $\mathrm{X}, \mathrm{Y}$ and $\mathrm{Z}$ standing for $\mathrm{C}$ or $\mathrm{T}$.

\section{Methods}

\section{1.Experimental}

Acetylacetone (99.5\%) was purchased at Fluka, $\mathrm{Na}_{2} \mathrm{SO}_{4}(>99.5 \%)$ at Merck, $\mathrm{D}_{2} \mathrm{O}(99.9 \%)$ and $\mathrm{NaCl}$ $(>99 \%)$ at Sigma-Aldrich. Double deuterated acetylacetone (AcAcD2) was prepared mostly following synthesis steps published in Dea Kin-Kin doctoral thesis. ${ }^{33}$ Briefly, synthesis consists in refluxing a mixture of acetylacetone and deuterated water $\left(D_{2} O\right)$ for approximately 4 hours at $80^{\circ} \mathrm{C}$, using a desiccant at the open part of the system to minimize the entry of atmospheric water. After reaching equilibrium at room temperature, organic and aqueous phases are 
separated by a decantation process, adding sodium chloride $(\mathrm{NaCl})$ and cooling the sample to improve the separation. We add a small quantity of sodium sulfate $\left(\mathrm{Na}_{2} \mathrm{SO}_{4}\right)$ to eliminate possible water impurities in the final product and decant this mixture at the end. During the deuteration procedure, exchange yields of $90 \%$ were reached for non-methyl hydrogens. The deuteration ratio was determined from infrared absorption band intensity ratio of hydrogenated and deuterated species assuming similar absorption coefficients. Products include both single and double deuterated species, with a yield of AcACD2 above 65\%. IR bands coming from $A c A c H 8, A c A c D 2$ and $A c A c D 1$ were used to estimate these ratios.

Matrix samples were obtained by direct deposition of a gas mixture containing deuterated acetylacetone and neon (Messer 5.0) in a ratio of 1-1.5:1000 onto a Csl substrate, cooled between 7 and $8 \mathrm{~K}$ inside a closed cycle He cryostat (APD Cryogenics Inc.). Deposition times varied from 30 to $40 \mathrm{~min}$, and the deposition rate was around $10 \mathrm{mmol} \mathrm{h}^{-1}$.

Infrared spectra were acquired using standard FT-IR spectrometer (Nicolet Nexus 870) and liquid nitrogen-cooled MCT detector. All the spectra were recorded in the transmission mode with a $0.5 \mathrm{~cm}^{-1}$ resolution. The IR beam path was purged with dry air.

Ultraviolet absorption spectra were acquired using a $0.6 \mathrm{~m}$ Jobin Yvon grating monochromator and a CCD camera (Andor DH720). We used a deuterium lamp as light source and sapphire as deposition window for these studies.

UV and IR induced isomerization experiments were performed using an Optical Parametric Oscillator (OPO) nanosecond laser from Continuum, pumped by the $355 \mathrm{~nm}$ line of a tripled $\mathrm{Nd}$ :YAG laser, $10 \mathrm{~Hz}$ repetition rate, wavelength range from $192 \mathrm{~nm}$ to $2700 \mathrm{~nm}$. The pulse energies were in the range of 1-6 mJ. Laser bandwidths for UV and IR wavelengths were around $7 \mathrm{~cm}^{-1}$ in both cases. Irradiation times varied typically from several minutes to several hours. Laser irradiation was stopped during measurements of FT-IR spectra.

\section{II.2. Calculations}

Geometry optimizations were performed for all isomers (keto and eight enol forms) of deuterated acetylacetone followed by frequency calculations. In all the steps we used DFT level of theory with B3LYP functional $\left.\right|^{34,35}$ and $6-311++g(3 d f, 3 p d)$ basis set. A very tight convergence criteria and an ultrafine optimization grid were also used. Vibrational frequencies were obtained by means of both harmonic and anharmonic approaches. For the presented harmonic spectra a 
scaling factor of 0.981 was used. This value was optimized to fit the theoretical results to the experimental values taking into account the interaction between the host and the molecule.

Rotational barriers between cis and trans positions of $\mathrm{OH} / \mathrm{OD}$ in open enol conformers of acetylacetone were obtained through relaxed scans, using $\mathrm{CCOH} / \mathrm{CCOD}$, respectively, dihedral angle as variable parameter, with 10 and 15 degrees steps. Frequency calculations were performed for initial, final and transition states (TS) in order to account for the Zero Point Energy corrections (ZPE). Each TS structure was optimized through a Berny optimization algorithm, and confirmed through an Internal Reaction Coordinate (IRC) calculation. Calculations related to the barrier were done at the MP2 level of theory using the same basis set as mentioned before. All calculations were performed using the Gaussian 09 package. ${ }^{36}$ Chemcraft software was used as graphical program for the visualization of the results. ${ }^{37}$

\section{Results and Discussion}

\section{1. Theoretical results}

Calculations show that the geometries of deuterated isomers are very similar to those of the related non-deuterated isomers. ${ }^{14}$ All enolic conformers have a planar structure (carbonated skeleton and CCOD dihedral). The geometry of CCC(D2) (see Fig. 1) is fully described in the Electronic Supplementary Information (ESI), Table S1. The stability order for the open enol conformers in deuterated isotopologues is the same as in the case of non-deuterated acetylacetone:

$$
\mathrm{CCC}>\mathrm{CTC}>\mathrm{CTT}>\mathrm{TCC}>\mathrm{TCT}>\mathrm{TTC}>\mathrm{CCT}>\mathrm{TTT}
$$

Energies relative to the CCC conformer for ACACD2 (CCC(D2)) are reported in Fig. 2. They differ from those of AcAcH8 by no more than $0.2 \mathrm{~kJ} / \mathrm{mol}$ in the different isotopologues, corresponding to the deuteration effect on the Zero Point Energy (ZPE) contribution, not large enough to perturb the order of stability. On the other hand, one can remark that the keto isomer is the most stable after the chelated enol. 


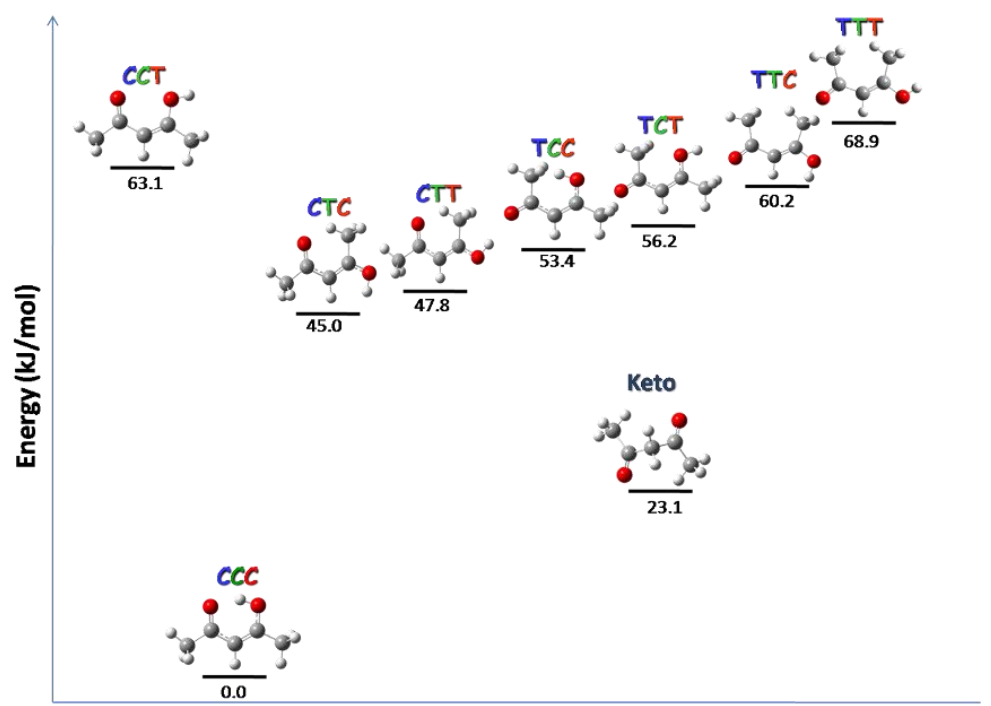

Figure 2: Schemes and relative energies $(\mathrm{kJ} / \mathrm{mol})$ of open enol conformers and keto isomer compared to the CCC conformer, in AcAcD2. Zero Point Energy is included in each reported value.

Calculated vibrational frequencies and intensities for the keto isomer and conformers were computed in order to identify the IR absorption bands of each of them and to obtain the aforementioned ZPE values. The whole set of theoretical data is reported in the ESI (Tables S2, S3 and S4). The most distinct feature in the case of ACACD2 conformers is the presence of OD stretching modes near $2790-2760 \mathrm{~cm}^{-1}$ for the open conformers, whilst the same mode for the CCC form is $500 \mathrm{~cm}^{-1}$ down shifted. This frequency range is especially important to check the formation of open conformers under laser irradiation.

\section{2. FT-IR Vibrational spectroscopy of as-deposited samples}

As previously noticed, our samples contain deuterated and non-deuterated acetylacetone. Figure 3 shows in the left panels the spectra of $\mathrm{AcAcH} 8$ (a) and of the deuterated species (b) in neon matrices at $7.6 \mathrm{~K}$. The latter spectrum (b) is obtained after subtraction of the bands of $\mathrm{AcAcH} 8$ from the spectrum of the as-deposited sample. The calculated spectrum of CCC(D2) in the harmonic approximation is displayed in panel (c) for comparison. Calculated frequency is scaled by the factor 0.981 for the better comparison with the experimental data. Frequencies obtained in the anharmonic approximation are reported in Table I, together with the scaled harmonic frequencies. The agreement between the theoretical spectrum (c) and the experimental one (b) for the most intense bands is very good, and we conclude that AcAcD2 in its chelated enol form is the main structure observed in the experimental spectrum (b). Nevertheless, there are several bands which do not correspond to CCC(D2) (see Fig. 3, right panel: zoom of $1340-1460 \mathrm{~cm}^{-1}$ region). When comparing experimental and theoretical spectra 
for double deuterated and monodeuterated conformers, we found that these bands correspond to the CCC forms of the monodeuterated species AcAcD1 i.e. of AcAcD1(CD) and AcAcD1(OD). In addition, similarly to the case of the non-deuterated molecule, we observe the keto tautomer in the deposited samples, assigning to it two weak vibrational bands at 1717.2 and $1185.4 \mathrm{~cm}^{-1}$. Theoretical calculations suggest that these frequencies are very close from one isotopologue to another (see ESI, Tables S2, S3, S4). The amount of keto tautomer is very low (approximately $1 \%)$, just as with the $\mathrm{AcAcH} 8$ isotopologue. This result shows that the keto-enol equilibrium is not significantly perturbed by deuteration.

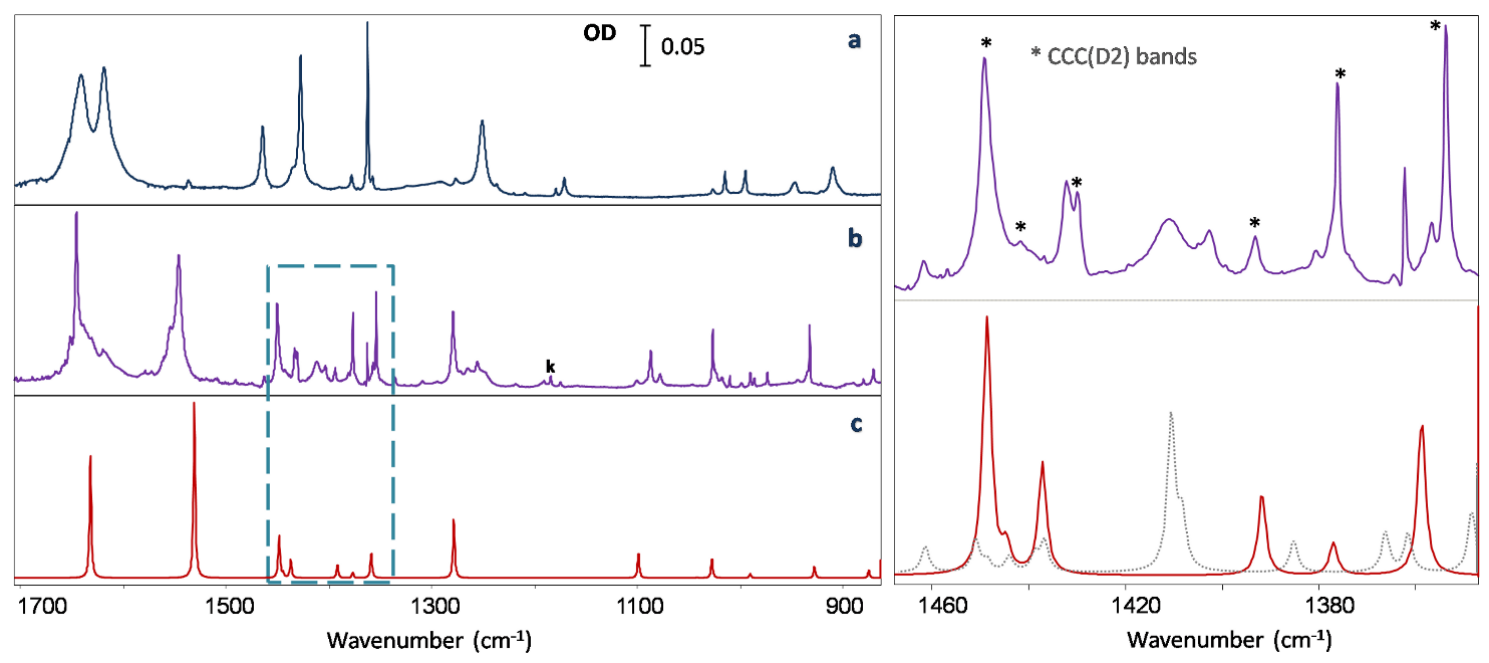

Figure 3: Left: a) As deposited acetylacetone (AcAcH8) in $\mathrm{Ne}$, b) As deposited deuterated acetylacetone in Ne (after subtraction of residual AcAcH8 bands), and c) Calculated spectrum of CCC(D2) (harmonic frequency calculation with a 0.981 scaling factor). Right: Zoom on the $1340-1470 \mathrm{~cm}^{-1}$ region: experimental spectrum (top) and theoretical spectra (bottom, ACACD2 red line and ACAcD1 - same amount of both isotopologues - grey dotted line). $k$ denotes keto band, $*$ denotes bands assigned to AcAcD2 in the zoomed region, the other bands are assigned to AcAcD1 (see Fig. 5). The theoretical spectrum is shown using a convolution with a Lorentzian profile of $2 \mathrm{~cm}^{-1}$ bandwidth.

\section{2. a. AcAcD2, CCC conformer}

In order to distinguish the bands from AcAcD2 to those from monodeuterated isotopologues, we made subtraction between two spectra of samples with different AcAcD2/AcAcD1 ratios (i.e. different deuteration yields of synthesis). The list of bands assigned to double deuterated CCC and the calculated bands of CCC(D2) are reported in Table I. 
Table I: CCC(D2) conformer assignment. Experimental frequencies of the chelated enol form of ACACD2 in a neon matrix, compared to experimental values obtain by Tayyari et al $^{32}$ in gas phase, calculated harmonic and anharmonic frequencies [B3LYP/6-311++G(3df,3pd)] $\left(\mathrm{cm}^{-1}\right)$. Intensities $(\mathrm{km} / \mathrm{mol})$ obtained in the harmonic approximation.

\begin{tabular}{|c|c|c|c|c|c|}
\hline \multirow{2}{*}{ Assignment $^{a}$} & \multirow{2}{*}{ Experiment } & \multirow{2}{*}{$\begin{array}{c}\text { Tayyari } \\
\text { (Gas) }\end{array}$} & \multicolumn{3}{|c|}{ Theoretical } \\
\hline & & & harmonic*sf ${ }^{b}$ & anharmonic & Intensity \\
\hline $\mathrm{v}_{\mathrm{a}} \mathrm{CH}_{3}$ (CO side) & $3034^{c}$ & 3018 & 3083.2 & 3003.2 & 10 \\
\hline $\mathrm{V}_{\mathrm{a}} \mathrm{CH}_{3}$ (OD side) & $3027^{c}$ & & 3078.3 & 2998.7 & 9 \\
\hline $\mathrm{v}_{\mathrm{a}} \mathrm{CH}_{3}$ (OD side) & & 2970 & 3031.5 & 2949.3 & 5 \\
\hline $\mathrm{v}_{\mathrm{a}} \mathrm{CH}_{3}$ (CO side) & & & 3021.5 & 2954.3 & 6 \\
\hline $\mathrm{v}_{\mathrm{s}} \mathrm{CH}_{3}$ (OD side) & $2951^{c}$ & 2940 & 2980.5 & 2928.5 & 8 \\
\hline $\mathrm{v}_{5} \mathrm{CH}_{3}$ (CO side) & & & 2976.4 & 2951.5 & 3 \\
\hline$v C D$ & 2304.5 & 2300 & 2328.7 & 2297.0 & 1 \\
\hline vOD & $2000^{c}$ & 2027 & 2158.3 & 1857.1 & 259 \\
\hline$v_{a}(C=C+C=0)$ & 1641.8 & 1633 & 1631.7 & 1616.5 & 263 \\
\hline$v_{s}(C=C+C=0)+\delta O D$ & 1544.2 & 1544 & 1530.6 & 1515.2 & 374 \\
\hline$\delta_{\mathrm{a}} \mathrm{CH}_{3}$ (OD side) & 1449.4 & 1448 & 1448.3 & 1436.7 & 87 \\
\hline $\mathrm{\delta}_{\mathrm{a}} \mathrm{CH}_{3}$ (CO side) & 1429.3 & 1448 & 1436.9 & 1432.6 & 39 \\
\hline$\delta_{5} \mathrm{CH}_{3}$ (OD side) & 1392.7 & & 1391.5 & 1390.5 & 28 \\
\hline$\delta_{5} \mathrm{CH}_{3}$ & 1376.1 & 1365 & 1376.8 & 1368.0 & 11 \\
\hline$\delta_{s} \mathrm{CH}_{3}(\mathrm{CO}$ side $)$ & 1354.0 & 1365 & 1358.5 & 1354.1 & 54 \\
\hline $\begin{array}{l}v_{s} C-C-C=C-C \text { ring } \\
\text { breath }\end{array}$ & 1279.5 & 1273 & 1278.4 & 1270.3 & 126 \\
\hline$\delta O D$ & 1088.6 & 1082 & 1098.9 & 1076.0 & 52 \\
\hline$\rho \mathrm{CH}_{3}$ (OD side) & 1029.5 & 1025 & 1027.5 & 1027.4 & 34 \\
\hline$\pi \mathrm{CH}_{3}$ (CO side) & 1020.6 & & 1027.2 & 1020.9 & 7 \\
\hline$\rho \mathrm{CH}_{3}(+\delta O D)$ & 993.9 & & 990.2 & 991.5 & 10 \\
\hline $\begin{array}{l}\text { vC- } \mathrm{CH}_{3}(\mathrm{CO} \text { side })+ \\
\rho \mathrm{CH}_{3}\end{array}$ & 936.3 & 936 & 927.8 & 933.4 & 25 \\
\hline$\Delta$ ring $+\rho \mathrm{CH}_{3}$ & 874.9 & 880 & 874.9 & 881.8 & 17 \\
\hline$\delta C D$ & 831.1 & & 831.6 & 837.1 & 0.5 \\
\hline YOD & 706.1 & 707 & 735.5 & 740.9 & 38 \\
\hline
\end{tabular}

${ }^{a}$ main characteristic motions; $\mathbf{v}$, stretching; $\delta$, in plane bending; $\boldsymbol{v}$, out of plane bending; $\rho$, in plane rocking; $\pi$, out of plane rocking; $\Delta$, in plane ring deformation; s, symmetric; a, asymmetric

b sf: scaling factor (0.981)

${ }^{\mathrm{c}}$ Broad bands

The agreement is good for both calculations even if the scaling factor underestimates the effect of the anharmonicity for the highest frequencies. Only the OD stretching mode which is the most anharmonic and the most perturbed by the $\mathrm{H}$ bond, is not very well reproduced.

In previous studies of deuterated acetylacetone in the gas phase, the authors suggest the presence of this stretching band around $2025 \mathrm{~cm}^{-1} \cdot{ }^{29,32,38}$ A closer look at this frequency region was required to find a possible assignment for it: a weak and broad band around $2000 \mathrm{~cm}^{-1}$ could correspond to $V_{O D}$ (see Fig. 4). The large red shift of $V_{O D}$ is due to the internal hydrogen bond. In 
fact, it induces an inversion in the energy ordering of $C D$ and $O D$ stretching modes, observed experimentally and theoretically (see Fig. 4 and Table I).

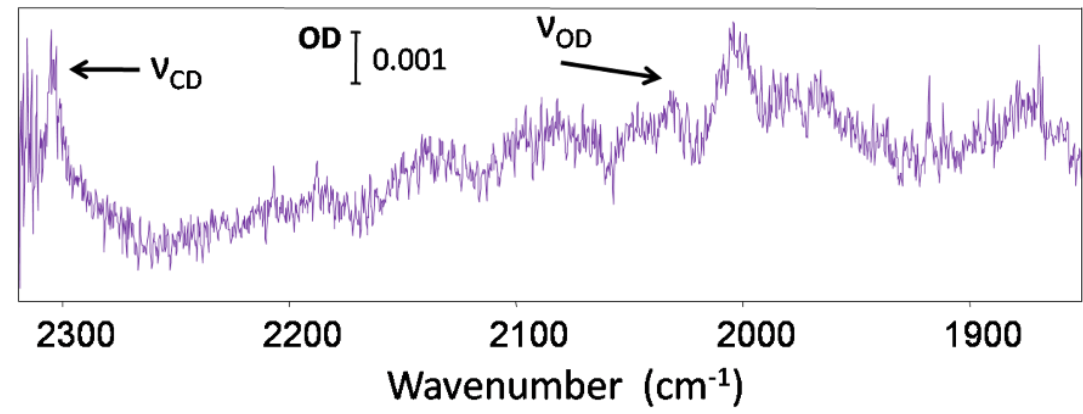

Figure 4: $1860-2320 \mathrm{~cm}^{-1}$ region in deposited deuterated acetylacetone spectrum. OD and CD stretching bands for AcAcD2 isotopologue are assigned.

It is known that for most molecules the position of the $\mathrm{OH} / \mathrm{OD}$ stretching mode allows easy the discrimination between non-deuterated and deuterated isotopologues. However in AcAcH8, despite its high intensity, the $\mathrm{OH}$ band is difficult to observe experimentally because it spreads over hundreds of wavenumbers due to the high delocalization of the hydrogen atom in the hydrogen bond, as suggested by the previous works in the gas phase at room temperature..$^{29,32}$ It is expected that the bandwidth should decrease significantly in the low temperature matrices ${ }^{38}$ however it remains very large even at lowest temperature, as proton delocalization is still high even in the cryogenic matrices. This fact makes the observation of the band very difficult and its maximum position can't be determined accurately. In particular, the $\mathrm{OH}$ stretching band of $\mathrm{AcAcH} 8$ was not clearly observed in neon matrices at $4 \mathrm{~K}^{14}$

One can see in Fig. 3 that most of the bands of AcAcD2 are narrower than those of AcAcH8. The decrease of the bandwidth for $\mathrm{OH}$ normal modes upon a H-D exchange was expected..$^{39}$ In both molecules, the stretching and especially the bending of the $\mathrm{OH} / \mathrm{OD}$ group contribute to several normal modes: it could explain in part, the global broadening of bands in $\mathrm{CCC}(\mathrm{H} 8)$ compared to $C C C(D 2)$. Table II reports FWHM of the main assigned lines of $C C C(D 2)$ and $C C C(H 8)$ in Ne, with a short description of the modes in order to directly compare both isotopologues. The $\mathrm{OH} / \mathrm{OD}$ stretching modes are not included in Table II because, as it was written above, $\mathrm{v}_{\mathrm{OH}}-\mathrm{CCC}(\mathrm{H} 8)$ was not observed. Thus as we observe the $v_{\mathrm{OD}}-\mathrm{CCC}(\mathrm{D} 2)$ band (Fig. 4), it should be narrower than the $\mathrm{V}_{\mathrm{OH}}-\mathrm{CCC}(\mathrm{H} 8)$ band. 
Table II: Bandwidths in Ne for some bands of the CCC conformer of AcAcH $8^{8}$ and AcAcD2. Only bands where a measurement of FWHM was possible are shown. The assignment is set according to ref.8, and pairing modes was made taking into account the most relevant motions involved in each mode. Position and width are in $\mathrm{cm}^{-1} . \mathrm{nm}$ : measurement was not possible.

\begin{tabular}{|c|c|c|c|c|}
\hline \multirow{2}{*}{ Assignment $^{a}$} & \multicolumn{2}{|c|}{ AcAcH8 } & \multicolumn{2}{|c|}{ AcAcD2 } \\
\hline & Position & Width & Position & Width \\
\hline$v_{a}(C=C+C=0)$ & $1642.0^{b}$ & 16 & 1641.8 & 2.5 \\
\hline $\mathrm{v}_{\mathrm{s}}(\mathrm{C}=\mathrm{C}+\mathrm{C}=\mathrm{O})+\delta O H$ & $1619.7^{b}$ & 11 & 1544.2 & 5.7 \\
\hline$\delta_{\mathrm{a}} \mathrm{CH}_{3}(\mathrm{OH}$ side) & 1465.1 & 4.6 & 1449.4 & 2.0 \\
\hline$\delta_{\mathrm{a}} \mathrm{CH}_{3}$ & 1435.8 & 6.6 & 1429.3 & 1.3 \\
\hline$\delta \mathrm{CH}_{3}$ & 1428.1 & 4.3 & 1376.1 & 0.8 \\
\hline$\delta_{5} \mathrm{CH}_{3}(\mathrm{OH}$ side) & 1378.6 & 2.6 & 1392.7 & 1.6 \\
\hline$\delta_{5} \mathrm{CH}_{3}$ (CO side) & 1362.9 & 1.5 & 1354.0 & 0.9 \\
\hline бОН & 1297.2 & 78 & 1088.6 & 2.3 \\
\hline$v_{s} C-C-C=C-C$ ring breath & 1251.4 & 7.3 & 1279.5 & 2.9 \\
\hline$\delta \mathrm{CH}_{\text {olefinic }}$ & 1171.5 & 3.3 & 831.1 & $n m$ \\
\hline $\mathrm{\rho CH}_{3}$ (OH side) & 1015.8 & 1.8 & 1029.5 & 1.3 \\
\hline $\mathrm{\rho CH}_{3}$ (CO side) & $995.2^{b}$ & 1.4 & 993.9 & 1.0 \\
\hline $\mathrm{YOH}$ & 947.9 & 5.5 & 706.1 & $n m$ \\
\hline$\Delta$ ring $+\rho \mathrm{CH}_{3}$ & 910.6 & 6.3 & 874.9 & 1.3 \\
\hline
\end{tabular}

a main characteristic motions; $\mathbf{v}$, stretching; $\delta$, in plane bending; $\boldsymbol{v}$, out of plane bending; $\rho$, in plane rocking; $\Delta$, in plane ring deformation; s, symmetric; a, asymmetric

${ }^{b}$ bands with shoulders

\section{2. b. Monodeuterated isotopologues (CCC(OD) and CCC(CD))}

AcAcD1 is always present in the samples as $C C C$ forms of $A c A c D 1(O D)$ and $A c A c D 1(C D)$. We were able to obtain the spectrum of AcAcD1 in Ne (Fig. 5 a) by subtracting spectra of samples with different deuteration ratios and to assign few bands of the monodeuterated isotopologues. It appears that the ratio between isotopomers $A C A C D 1(O D)$ and $A C A C D 1(C D)$ is roughly the same in all the samples, close to 50/50 (a precise measurement is not possible). The band assignment to a particular isotopomer is complicated because $\operatorname{AcAcD1}(\mathrm{OD})$ and $\operatorname{AcAcD1}(\mathrm{CD})$ have many modes with very similar frequencies. Nevertheless, we were able to identify some bands for each isotopologue using the theoretical spectra (Fig. $5 \mathrm{~b}$ and c). These bands suggest that similarly to $A c A c D 2$ and $A c A c H 8$, those corresponding to $A c A c D 1(O D)$ are narrower than those of $A c A C D 1(C D)$. Additional bands can be tentatively assigned to each isotopologue following this remark. The experimental frequencies compared to calculations are reported in Table III. 
Considering that $A c A c D 2$ and $A c A c D 1(O D)$ in one hand, and $A c A c H 8$ and $A C A c D 1(C D)$ in the other hand have similar bandwidths we conclude that the $\alpha$ hydrogen (olefinic hydrogen) does not have a wide impact in the band broadening.

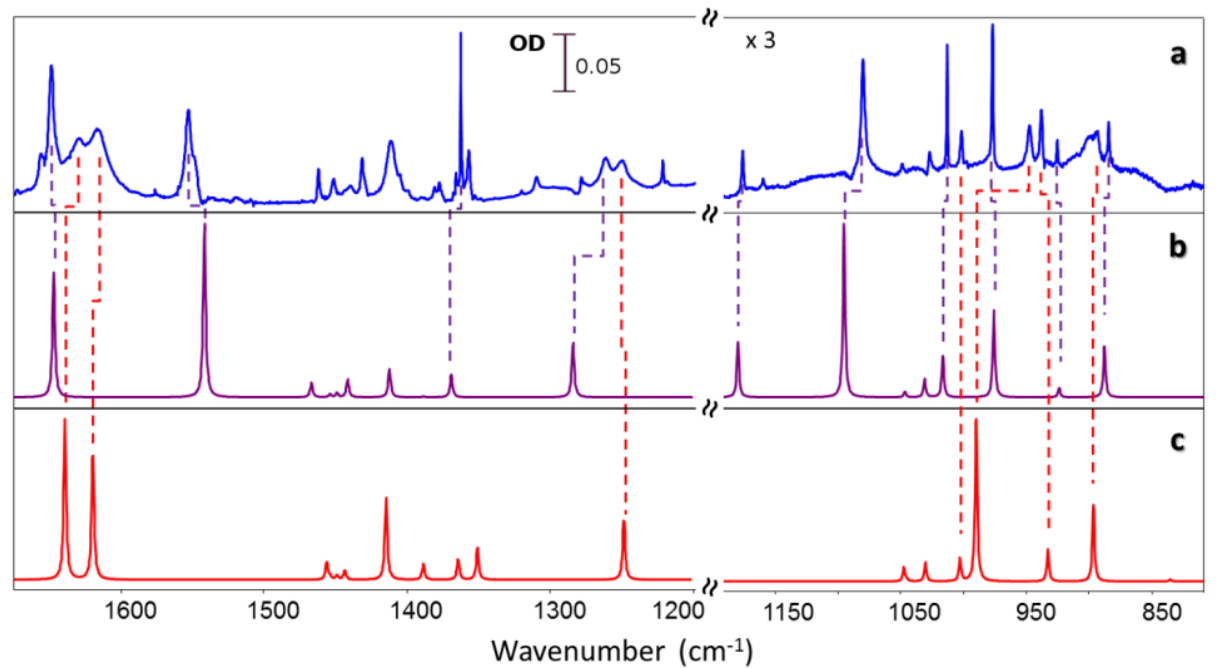

Figure 5: a) IR spectrum of monodeuterated isotopologues (obtained after removing AcAcD2 and AcAcH8 from the original spectrum); IR theoretical spectra - Lorentzian bandwidths of $2 \mathrm{~cm}^{-1}$-in the scaled harmonic approximation of CCC forms of b) AcAcD1(OD) and c) AcAcD1(CD) isotopologues. Zoom (x3) below $1200 \mathrm{~cm}^{-1}$ for a better comparison. Assignment is shown with dashed colored lines for some of the most important bands. 
Table III: Experimental frequencies $\left(\mathrm{cm}^{-1}\right)$ of the chelated enol form of AcAcD1(OD) and AcAcD1(CD) conformers in Ne, compared to calculated harmonic and anharmonic frequencies [B3LYP/6-311++G(3df,3pd)]. Experimental bandwidths $\left[\Delta\left(\mathrm{cm}^{-1}\right)\right]$ and intensities obtained in the harmonic approximation $(\mathrm{km} / \mathrm{mol})$ are also reported. $n$ m: measurement was not possible.

\begin{tabular}{|c|c|c|c|c|c|c|c|c|c|c|c|}
\hline \multicolumn{6}{|c|}{ CCC(OD) } & \multicolumn{6}{|c|}{$\mathrm{CCC}(\mathrm{CD})$} \\
\hline \multirow[t]{2}{*}{ Assignment $^{\mathrm{a}}$} & \multirow[t]{2}{*}{$\begin{array}{l}\text { CCC-OD } \\
\text { Exp. }\end{array}$} & \multirow[t]{2}{*}{$\Delta$} & \multicolumn{2}{|c|}{$\begin{array}{l}\text { Theo. harm. *sf }{ }^{b} \\
\text { (Anharm.) }\end{array}$} & \multirow[t]{2}{*}{ Int. } & \multirow{3}{*}{\begin{tabular}{|l|}
\multicolumn{2}{|c}{ Assignment $^{\mathrm{a}}$} \\
$\mathrm{v} C \mathrm{CD}$ \\
$\mathrm{v}_{\mathrm{a}}(\mathrm{C}=\mathrm{C}+\mathrm{CO})$
\end{tabular}} & \multirow{2}{*}{$\begin{array}{l}\text { CCC-CD } \\
\text { Exp. } \\
2306.8\end{array}$} & \multirow[t]{2}{*}{$\Delta$} & \multicolumn{2}{|c|}{$\begin{array}{l}\text { Theo. harm. }{ }^{*} \mathbf{s f}^{b} \\
\text { (Anharm.) }\end{array}$} & \multirow{2}{*}{$\begin{array}{r}\text { Int. } \\
0.8\end{array}$} \\
\hline & & & & & & & & & 2328.7 & (2296.2) & \\
\hline$v_{a}(C=C+C O)$ & 1648.7 & 3.9 & 1641.9 & (1625.5) & 273 & & 1630.5 & 14 & 1634.0 & $(1608.6)$ & 355 \\
\hline$v_{s}(C=C+C O)+\delta O D$ & 1552.7 & 4.7 & 1536.7 & (1517.1) & 384 & $v_{s}(C=C+C O)+\delta O H$ & 1616.8 & 18 & 1614.6 & (1603.9) & 283 \\
\hline$\delta_{\mathrm{a}} \mathrm{CH}_{3}(\mathrm{OD}$ side $)+\delta \mathrm{CH}$ & 1461.2 & $n m$ & 1462.1 & (1454.2) & 32 & $\delta_{\mathrm{a}} \mathrm{CH}_{3}(\mathrm{OH}$ side $)+\delta \mathrm{OH}$ & 1451.2 & $n m$ & 1451.5 & (1446.9) & 38 \\
\hline \multirow[t]{2}{*}{$\delta_{\mathrm{a}} \mathrm{CH}_{3}(\mathrm{CO}$ side $)$} & 1431.2 & $n m$ & 1436.9 & $(1427.8)$ & 21 & $\delta_{\mathrm{a}} \mathrm{CH}_{3}(\mathrm{CO}$ side $)+\delta \mathrm{OH}$ & 1439.7 & $n m$ & 1438.9 & $(1427.8)$ & 20 \\
\hline & & & & & & $\begin{array}{l}\delta \mathrm{OH}+\mathrm{v}_{\mathrm{s}} \text { (carbon } \\
\text { skeleton) }\end{array}$ & 1411.3 & 7.7 & 1410.1 & (1397.8) & 180 \\
\hline$\delta_{\mathrm{a}} \mathrm{CH}_{3}(\mathrm{OD}$ side) & 1404.5 & $n m$ & 1407.7 & (1399.8) & 64 & $\delta_{5} \mathrm{CH}_{3}$ (OH side) & 1380.7 & $n m$ & 1384.1 & (1365.8) & 35 \\
\hline$\delta_{5} \mathrm{CH}_{3}$ ( $\mathrm{CO}$ side) & 1361.7 & 0.8 & 1364.6 & (1361.4) & 50 & $\delta_{5} \mathrm{CH}_{3}(\mathrm{CO}$ side) & 1356.6 & 3.0 & 1359.9 & (1358.9) & 45 \\
\hline $\begin{array}{l}V_{s} \text { (carbon skeleton) } \\
+(\delta \mathrm{OD})\end{array}$ & 1261.4 & 8.5 & 1279.7 & (1260.7) & 119 & $\begin{array}{l}\text { vs (carbon skeleton) } \\
+\delta \mathrm{OH}\end{array}$ & 1249.1 & 10.2 & 1244.3 & $(1232.1)$ & 135 \\
\hline$\delta \mathrm{CH}$ & 1175.0 & 1.7 & 1175.6 & $(1170.2)$ & 21 & & & & & & \\
\hline$\delta O D$ & 1079.9 & 3.5 & 1091.4 & (1039.3) & 66 & & & & & & \\
\hline$\pi \mathrm{CH}_{3}$ (CO side) & 1027.0 & $n m$ & 1027.4 & (1025.0) & 7 & $\pi \mathrm{CH}_{3}$ (CO side) & 1027.0 & $n m$ & 1027.2 & (1024.3) & 8 \\
\hline $\mathrm{\rho CH}_{3}$ (OD side) & 1013.0 & 0.8 & 1013.0 & (1013.7) & 16 & $\mathrm{\rho CH}_{3}$ & 1048.9 & $n m$ & 1044.4 & (1041.4) & 6 \\
\hline$\rho \mathrm{CH}_{3}$ (CO side) $+\delta O D$ & 976.7 & 1.1 & 972.4 & (978.9) & 33 & $\mathrm{\rho CH}_{3}$ & 1001.6 & 1.8 & 999.7 & (1001.4) & 10 \\
\hline$\Delta$ ring $+\rho \mathrm{CH}_{3}$ & 925.2 & 0.8 & 920.6 & (923.3) & 4 & $\Delta$ ring $+\rho \mathrm{CH}_{3}$ & 938.2 & 2.4 & 929.8 & (933.0) & 14 \\
\hline$\Delta$ ring $+\rho \mathrm{CH}_{3}(\mathrm{CO}$ side $)$ & 884.1 & 1.5 & 884.7 & (890.5) & 20 & $\Delta$ ring $+\rho \mathrm{CH}_{3}(\mathrm{CO}$ side $)$ & 893.9 & $n m$ & 893.7 & (907.3) & 32 \\
\hline${ }_{\nu C H}$ & 777.5 & $n m$ & & & & & & & & & \\
\hline YOD & 706.1 & $n m$ & 732.4 & (734.1) & 50 & YOH & 947.4 & 3.6 & 986.9 & (986.2) & 70 \\
\hline
\end{tabular}

a main characteristic motions; $v$, stretching; $\delta$, in plane bending; $\boldsymbol{\nu}$, out of plane bending; $\boldsymbol{\rho}$, in plane rocking; $\pi$, out of plane rocking; $\Delta$, in plane ring deformation; $\mathbf{s}$, symmetric; a, asymmetric;

bs: scaling factor (0.981) 


\section{3. UV irradiation and open conformers}

UV irradiation of matrix samples doped with acetylacetone induces the photo-isomerization of the enolic form and the production of open enol conformers. In our previous studies with AcAcH8 isolated in neon matrices, we showed that the produced open conformers can be separated in two groups: a first one, reduced to CTC, growing from CCC upon irradiation at 266 $\mathrm{nm}$ and disappearing in a prolonged irradiation, and a second group, including mainly TCC with a very weak amount of TTC, growing slower upon the same irradiation. ${ }^{14} \mathrm{~A}$ similar behavior is expected with AcAcD2 isolated in neon matrices. With the OPO laser as the UV irradiation source, it is possible to excite acetylacetone in a broad range of UV wavelengths. We observe different behaviors according to the different wavelengths used in the $250-280 \mathrm{~nm}$ range, but in any case, new bands are growing while the CCC conformer is disappearing. The spectra are complex but these bands can be classified in two groups of open conformers. A clear assignment was possible in each group based on two additional processes: (i) the relative intensities of the new bands change in time without irradiation, meaning that the spectra contained the signature of stable and meta-stable conformers; (ii) IR laser irradiation performed after UV irradiation affects differently the produced conformers.

In order to precise the efficiency of the UV irradiation on the various conformers of acetylacetone, we recorded first the UV absorption spectra of acetylacetone isolated in solid neon. These spectra helped in the choice of the excitation wavelengths to induce photoisomerization. UV spectra are described in the next part, followed by the results on the first and the second groups of conformers.

\section{III.3.a. UV absorption spectra of acetylacetone in solid neon}

The UV absorption of $\mathrm{ACACH} 8$ (CCC form) in neon matrices is shown in Fig. 6, left panel - black solid line. Electronic absorption spectra of acetylacetone in different matrices were already published, but the spectrum in solid neon was lacking. ${ }^{40}$ The CCC absorption band is slightly red shifted from the gas phase ${ }^{41}$ with a maximum of absorption at $265 \mathrm{~nm}$ in $\mathrm{Ne}(262.7 \mathrm{~nm}$ in the gas phase). The maximum of the band was also found around $265 \mathrm{~nm}$ in $\mathrm{N}_{2}$ and was red shifted in $\mathrm{Ar}$ and Xe (maximum around $270 \mathrm{~nm}$ ). ${ }^{12}$ All these results indicate a weak effect of the matrix on the electronic structure of acetylacetone. 

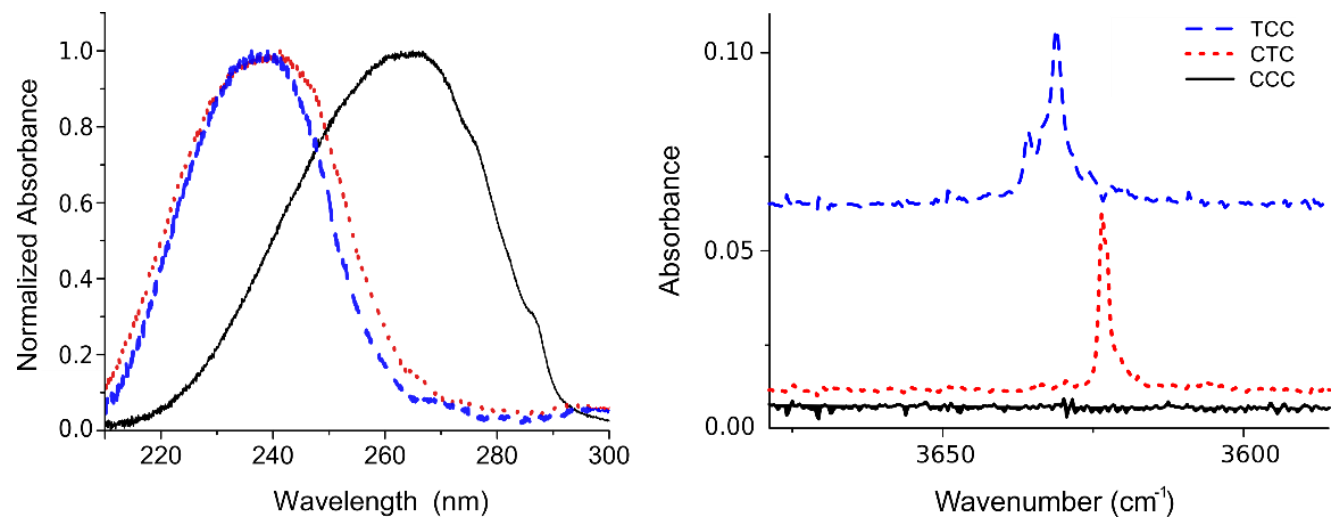

Figure 6: Left: Electronic absorption spectra of acetylacetone (AcAcH8). CCC (black solid line), first group (CTC) (red dots) and second group (mainly TCC) (blue dash) of conformers; Right: IR spectra corresponding to each group. The open conformer spectra are obtained combining different weighted spectra in order to get separated spectra for each conformer.

We benefit from our previous study of photo-isomerization of $\mathrm{AcAcH} 8$ in $\mathrm{Ne}^{14}$ to use the best experimental conditions to get samples with almost only one conformer trapped and we obtain the spectra of CTC and TCC displayed in Fig. 6, left panel (red dot and blue dash lines respectively). In the spectra shown in Fig. 6, the CCC conformer spectrum was subtracted from the open enol conformer spectra for better clarity, and spectra were normalized.

The three conformers have broad absorption bands. The UV absorption spectra of CTC and TCC are very close (maxima around $240 \mathrm{~nm}$ and $237 \mathrm{~nm}$ respectively). The IR spectra of the same samples in the frequency range of free $\mathrm{OH}$ stretching modes are displayed in the right panel of Fig. 6 to confirm the assignments: CCC- black solid (no free OH), CTC -red dot and TCC - blue dash.

Theoretical calculations on the electronic states of AcAcH8 (CR-EOMCCSD(T) method) ${ }^{40}$ reported a difference of only $7 \mathrm{~nm}$ in the electronic absorption of CTC and TCC, whereas a blue shift of 19 $\mathrm{nm}$ was calculated between CTC and CCC: these estimations are in good agreement with the present results in Ne.

The UV absorption spectra of deuterated acetylacetone should be very similar to those of $\mathrm{AcAcH} 8$, because of the small perturbation due to deuteration. This assumption was confirmed by recording the absorption spectrum of $\mathrm{AcAcD} 2 / \mathrm{Ne}$ after deposition to get the electronic 
absorption spectrum of the $\mathrm{CCC}$ form. We use then the clear results obtained with AcAcH8 to choose the UV wavelengths for the photo-isomerization experiments.

\section{3. b. First group of deuterated conformers}

In order to obtain mostly the first group, we irradiated the deposited sample in the red part of the CCC absorption, at $280 \mathrm{~nm}$, far from the maximum of absorption of the other conformers and especially that of CTC (see Fig. 6). In Fig. 7 we can observe the simultaneous decrease of CCC with the increase of the two different groups of conformers. These groups differ by their kinetics, in the same way as in $\mathrm{AcAcH} 8 / \mathrm{Ne}$ experiments. ${ }^{14}$ When $\mathrm{CCC}$ is almost depleted, the first group is predominant. Its spectrum is reproduced in Fig. 8. The second group will be discussed in the next section.

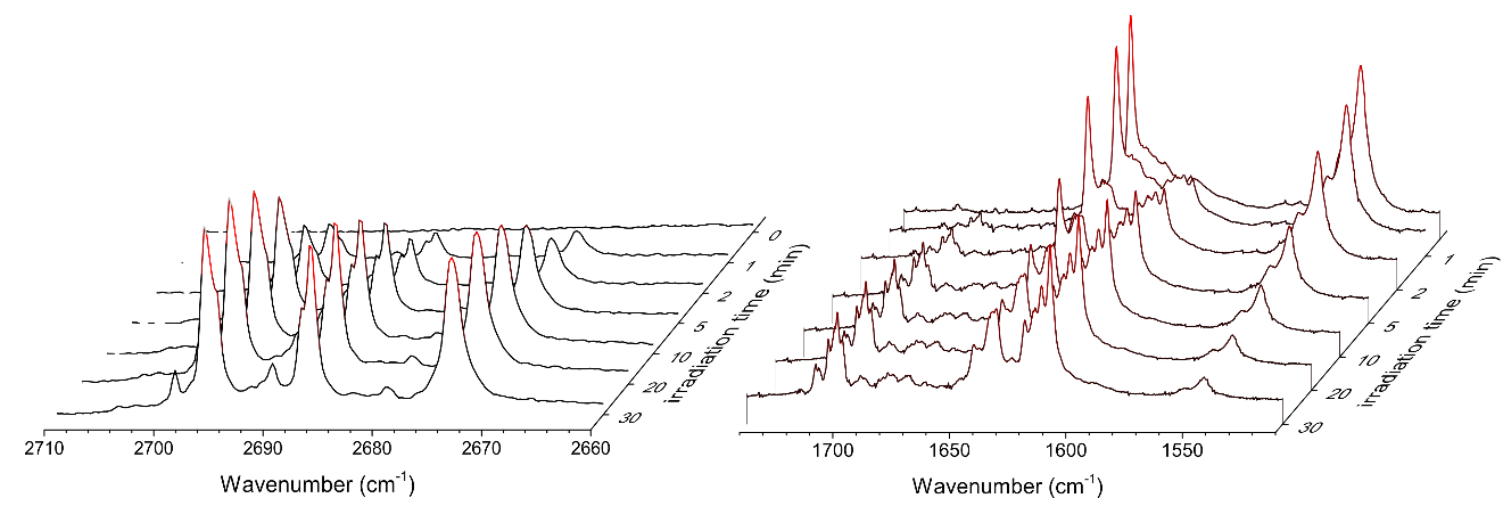

Figure 7: Evolution of acetylacetone IR spectrum under $280 \mathrm{~nm}$ laser irradiation (from the rear to the front). Left: $O D$ stretching region of non-chelated conformers (zoom 14x). Right: $C=O$ and $C=C$ stretching region. The first group of conformers is mainly produced but a small amount of second group is also observed in the spectra.

Figure 8, panel a, shows the most relevant regions of the IR spectrum of the first group in a neon matrix. The bands coming from $\mathrm{CCC}$ and from the second group have been subtracted from the original spectrum. Theoretical spectra of $\mathrm{CTC}(\mathrm{D} 2)$ and $\mathrm{CTT}(\mathrm{D} 2)$ are also reported in Fig. 8 (top panel) for comparison. They allow the assignment of most of the intense bands to these two species. Bands in the $2660-2710 \mathrm{~cm}^{-1}$ region (Fig. 8, left) correspond to the OD stretching modes of the deuterated isotopologues. Their number should give an idea of the number of produced conformers. However, because of the mixture of double and mono deuterated isotopologues, these $O D$ modes could belong to $A C A C D 2$ and $A C A C D 1(O D)$ open conformers. In fact, experiments were performed with different $A c A c D 1 / A c A c D 2$ ratios. $A c A c D 1$ bands can be easily 
observed in some spectra whereas the IR spectrum of Fig. 8, panel a, corresponds to a sample with a negligible amount of ACACD1. On the other hand, some bands in the spectrum exhibit a doublet structure which comes from site effects. Such doublets are also observed in nondeuterated conformers trapped in solid neon. The presence of different sites is confirmed with annealing effects. The site structure is more pronounced in the spectra of modes involving significantly OD motion, e.g. OD stretching modes and OD in-plane bending modes (group of doublets near $950 \mathrm{~cm}^{-1}$ ).

Surprisingly, when leaving the sample in the dark, we observe an evolution in the spectrum of open conformers: some bands increase while others decrease. The corresponding difference spectrum is displayed in Fig. 8, panel b. This change is attributed to an interconversion between CTT and CTC. The process is very slow, with a kinetic rate estimated at $10^{-7} \mathrm{~s}^{-1}$ from experimental measurements. This result gives an important information about conformers stability but also a confirmation of the attribution of the lines of the most stable conformer (CTC with the lowest energy, see Fig. 2). One can notice that the spontaneous CTT $\rightarrow$ CTC interconversion depends on the site where CTT(D2) is trapped, as can be seen in Fig. 8, panel b.

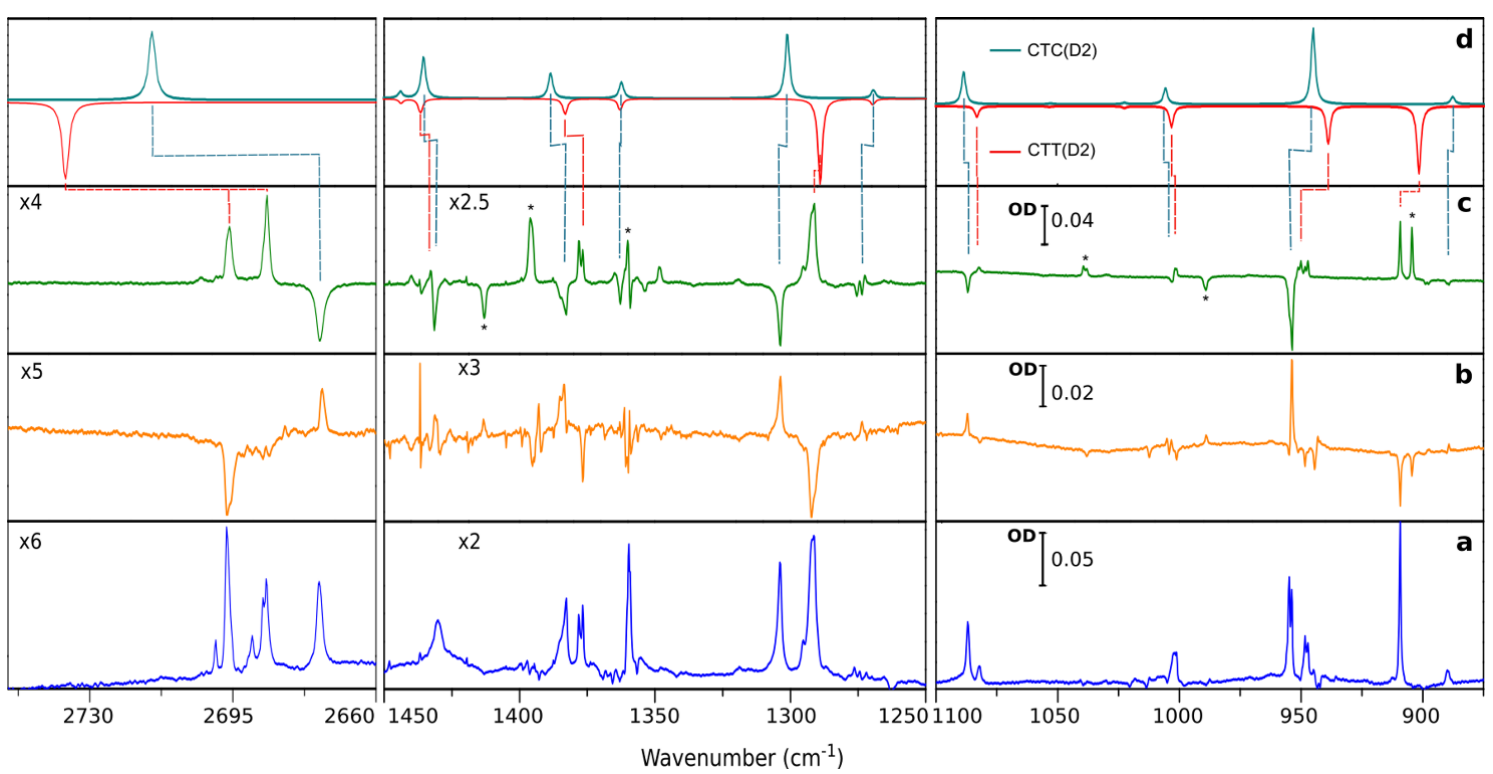

Figure 8: a) IR spectra of the first group of conformers (bands from CCC and from the second group are subtracted from the original spectrum), b) Difference IR spectrum between the sample just after UV irradiation and $68 \mathrm{~h}$ later in the dark, c) Difference IR spectrum between after and before IR laser irradiation at $5235 \mathrm{~cm}^{-1}$, obtained from a sample with a relatively high AcAcD1/AcAcD2 ratio; AcAcD1(OD) bands are marked with *, d) IR theoretical spectrum in the harmonic approximation (scaled by 0.981 ) of CTC(D2) (blue up) and CTT(D2) (red down) conformers (Lorentzian bandwidths of $2 \mathrm{~cm}^{-1}$ ); the positive/negative spectra are set in order to compare to panel b showing more stable (positive)/ less stable (negative) species. Zooms in the left and middle panels refer to the optical density of the right panel. 
In order to confirm and complete the previous assignment, we performed IR laser irradiation experiments with the laser frequency in the range of the OD stretching first overtone. The vibrational excitation of the fundamental $\mathrm{OH}$ mode in open conformers of $\mathrm{AcAcH} 8$ was found to promote isomerization between $\mathrm{XYC}$ and $\mathrm{XYT}$ conformers ( $\mathrm{X}$ and $\mathrm{Y}$ being $\mathrm{C}$ or $\mathrm{T}$ ). ${ }^{23}$ The region of the first OD overtones was not recorded in the IR absorption spectra. We found and assigned them by scanning the OPO laser frequency in the region predicted by the anharmonic calculations. The CTC $\leftrightarrow$ CTT interconversion is effectively observed when the laser is in resonance with the first overtone. The effect of IR irradiation at $5235 \mathrm{~cm}^{-1}$ is displayed in Fig. 8, panel c. In this case, CTC bands are depleted while those of CTT increase in intensity. An irradiation at $5280 \mathrm{~cm}^{-1}$ produces the $\mathrm{CTT} \rightarrow \mathrm{CTC}$ interconversion, making the process reversible. Furthermore, after IR irradiation at $5235 \mathrm{~cm}^{-1}$, CTT converts back to CTC once the IR laser is turned off, similarly to what happens after UV irradiation. The overtones of the three main OD stretching bands of Fig. 8, panel c are obtained and the values are reported in Table IV, in comparison with theoretical estimations calculated within the anharmonic approach. These experiments proved that the three OD bands (Fig. 8 a, left panel) belong to AcAcD2 open conformers - one to CTC(D2) and two to CTT(D2) -, and not to the monodeuterated isotopologue.

\begin{tabular}{|c|c|c|}
\hline & $\begin{array}{c}V_{\text {anharmonic }} / \mathrm{cm}^{-1} \\
\text { (Theoretical) }\end{array}$ & $\begin{array}{l}V_{\text {anharmonic }} / \mathrm{cm}^{-1} \\
\text { (Experimental) }\end{array}$ \\
\hline CTC & 5255 & 5235 \\
\hline \multirow{2}{*}{ CTT } & \multirow{2}{*}{5279} & 5260 \\
\hline & & 5280 \\
\hline TCC & 5230 & 5243 \\
\hline TCT & 5289 & 5280 \\
\hline
\end{tabular}

Combining the information from all the experiments and theoretical calculations, we conclude that the conformers produced in the first group are CTC(D2) and CTT(D2). Experimental frequencies and calculated values for CTC(D2) and CTT(D2) conformers are summarized in Table V. One can notice that there is no obvious narrowing of the CTC bands from AcAcH8 to AcAcD2, 
even on the $\mathrm{OH} / \mathrm{OD}$ stretching bands (bandwidths of $1.7 \mathrm{~cm}^{-1}$ in AcAcH8 and $1.5 \mathrm{~cm}^{-1}$ in AcAcD2).

The large bandwidth difference observed only between the chelated enols allows to conclude that highest influence of deuteration is on intramolecular hydrogen bond properties.

Table V: First group of conformers: experimental frequencies $\left(\mathrm{cm}^{-1}\right)$ in Ne compared to theoretical frequencies $\left(\mathrm{cm}^{-1}\right)$ [B3LYP/6-311++G(3df,3pd)]. Theoretical values in scaled harmonic approximation (and anharmonic approximation). Intensities $(\mathrm{km} / \mathrm{mol})$ obtained in the harmonic approximation.

\begin{tabular}{|c|c|c|c|c|c|}
\hline \multirow{2}{*}{ Assignments $^{a}$} & \multirow{2}{*}{ Experimental } & \multicolumn{3}{|c|}{ Theoretical } & \multirow[t]{2}{*}{ Intensity } \\
\hline & & СТC & & TTT & \\
\hline \multirow{2}{*}{ vOD } & $2696.5^{b}$ & & & & 52 \\
\hline & $2686.8^{b}$ & & 2121.4 & $(2684.0)$ & 53 \\
\hline vOD & 2674.3 & 2706.4 (2672.1) & & & 29 \\
\hline$v_{a}(C=C+C O)$ & 1707.7 & $1701.6(1701.4)$ & & & 170 \\
\hline$v_{a}(C=C+C O)$ & 1698.8 & & 1699.3 & $(1694.4)$ & 171 \\
\hline$v_{s}(C=C+C O)$ & 1632.9 & & 1617.7 & $(1603.3)$ & 481 \\
\hline$v_{s}(C=C+C O)$ & 1610.0 & $1597.1(1566.1)$ & & & 545 \\
\hline$\delta_{\mathrm{a}} \mathrm{CH}_{3}$ (OD side) & 1433.1 & & 1431.9 & $(1427.7)$ & 41 \\
\hline$\delta_{\mathrm{a}} \mathrm{CH}_{3}$ (OD side) & 1431.4 & $1431.0(1418.0)$ & & & 80 \\
\hline$\delta_{5} \mathrm{CH}_{3}$ (OD side) & 1382.8 & $1357.7(1378.4)$ & & & 49 \\
\hline$\delta_{5} \mathrm{CH}_{3}$ (OD side) & 1376.7 & & 1378.8 & $(1373.0)$ & 46 \\
\hline$\delta_{s} \mathrm{CH}_{3}(\mathrm{CO}$ side $)$ & 1359.8 & 1358.1 (1351.7) & & & 30 \\
\hline$\delta_{5} \mathrm{CH}_{3}$ (CO side) & 1359.8 & & 1358.5 & $(1352.7)$ & 34 \\
\hline$\delta_{5} \mathrm{CH}_{3}+v\left(\mathrm{C}-\mathrm{CH}_{3}\right)(\mathrm{OD}$ side $)$ & 1304.1 & $1296.0(1288.8)$ & & & 122 \\
\hline$\delta_{5} \mathrm{CH}_{3}+v\left(\mathrm{C}-\mathrm{CH}_{3}\right)(\mathrm{OD}$ side) & $\begin{array}{l}1292.5^{b} \\
1291.2^{b}\end{array}$ & & 1285.0 & $(1275.3)$ & 251 \\
\hline $\begin{array}{l}\mathrm{v}\left(\mathrm{C}-\mathrm{CH}_{3}\right)(\mathrm{CO} \text { side })+\mathrm{v}(\mathrm{C}-\mathrm{O}) \\
+\delta \mathrm{CH}_{3}\end{array}$ & 1273.5 & $1265.4(1249.6)$ & & & 16 \\
\hline $\begin{array}{l}v\left(\mathrm{C}-\mathrm{CH}_{3}\right)(\mathrm{CO} \text { side })+v(\mathrm{C}-\mathrm{O}) \\
+\delta \mathrm{CH}_{3}\end{array}$ & 1273.5 & & 1265.7 & (1258.9) & 17 \\
\hline$\rho \mathrm{CH}_{3}$ (CO side) & 1087.0 & 1085.2 (1079.6) & & & 63 \\
\hline$\rho \mathrm{CH}_{3}$ (CO side) & 1082.7 & & 1079.8 & $(1078.2)$ & 18 \\
\hline$\rho \mathrm{CH}_{3}$ (OD side) & 1001.3 & 1002.6 (999.1) & & & 30 \\
\hline$\rho \mathrm{CH}_{3}$ (OD side) & 1001.3 & & 1000.1 & (994.6) & 35 \\
\hline$\rho \mathrm{CH}_{3}(\mathrm{CO}$ side $)+\delta \mathrm{OD}$ & $\begin{array}{l}954.9^{b} \\
953.8^{b}\end{array}$ & $(934.5)$ & & & 145 \\
\hline$\rho \mathrm{CH}_{3}(\mathrm{CO}$ side $)+\delta \mathrm{OD}$ & $\begin{array}{l}948.4^{b} \\
947.2^{b}\end{array}$ & & 935.8 & (936.6) & 64 \\
\hline$\delta O D$ & 909.4 & & 898.7 & (901.1) & 113 \\
\hline$\delta O D+\delta C D$ & $\begin{array}{l}890.1^{b} \\
889.4^{b}\end{array}$ & (886.1) & & & 14 \\
\hline
\end{tabular}

a main characteristic motions; $\mathbf{v}$, stretching; $\boldsymbol{\delta}$, in plane bending; $\boldsymbol{\rho}$, in plane rocking; $\boldsymbol{\Delta}$, in plane ring deformation; s, symmetric; a, asymmetric

${ }^{b}$ bands with doublets due to sites effects

The first group of open conformers was reduced to CTC in the case of AcAcH8 trapped in Ne. A fast CTT $\rightarrow$ CTC interconversion was assumed to explain the absence of CTT, in comparison with 
the behavior of irradiated AcAcH8 in other matrices where CTT was observed. This assumption is confirmed by the deuteration effect: the tunneling process at play in the CTT $\rightarrow$ CTC interconversion is slower in the case of ACAcD2, allowing the detection of CTT in solid neon.

\section{3. c. Second group of deuterated conformers}

After depletion of the CCC conformer upon irradiation at $280 \mathrm{~nm}$, samples were irradiated at $260 \mathrm{~nm}$ to enhance the production of the second group of conformers. At $260 \mathrm{~nm}$, the absorption of the second group is lower than that of the first one while the CCC can still absorb and react. The second group is the only one growing under $260 \mathrm{~nm}$ irradiation.

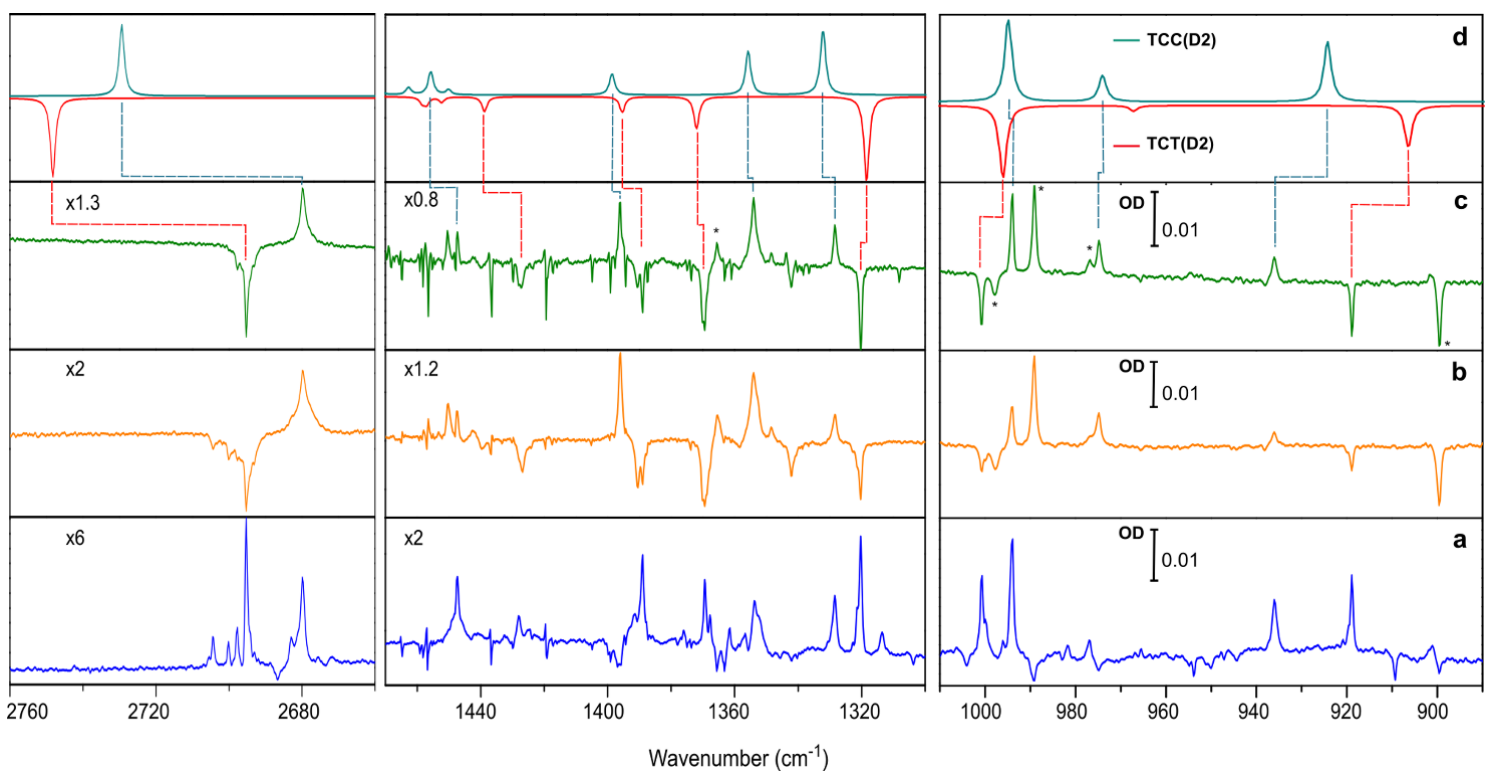

Figure 9: a) IR spectra of the second group of isomers (negative bands come from non-compensated subtraction of first group and $\mathrm{H} 8$ isomers), b) Difference IR spectrum between the sample just after UV irradiation and $72 \mathrm{~h}$ after in the dark, c) Difference IR spectrum after and before IR laser irradiation at $5280 \mathrm{~cm}^{-1}$, obtained from a sample with a relatively high AcAcD1/AcAcD2 ratio; AcAcD1(OD) bands are marked with *, d) IR theoretical spectrum in the harmonic approximation (scaled by 0.981 ) of TCC(D2) (blue up) and TCT(D2) (red down) conformers. Zooms in the left and middle panels refer to the optical density of the right panel.

The spectrum of the second group is shown in Fig. 9, panel a. Two strong bands are observed in the OD stretching region. One decreases while the other increases in the dark (Fig. 9, panel b). Consequently, we assign them to two conformers prone to interconversion process, similarly to the CTT/CTC pair. Kinetics of this process is slow: the kinetic constant is estimated around $10^{-6} \mathrm{~s}^{-}$ 1 , which is one order of magnitude larger than for the CTT/CTC pair. We also performed IR laser irradiation in the range of OD stretching overtones, similarly to the experiments with the first 
group, and we observed the same behavior, i.e. the reversible conversion of one species to the other (Fig.9, panel c). Overtones measurements are reported in Table IV.

Combining the information coming from all the experimental and theoretical data, we conclude that the second group is formed by $\operatorname{TCC}(\mathrm{D} 2)$ and TCT(D2). The theoretical spectra of these two conformers are reported in Fig. 9, panel d for comparison. Experimental frequencies and calculated values for conformers assigned to the second group are summarized in Table VI. Importantly, the TCT conformer is clearly detected in AcAcD2/Ne samples while it was not observed in $\mathrm{AcAcH} 8 / \mathrm{Ne}$ samples. As in the case of the first group, there is a slow quantum tunneling of the deuterium, compared to the measurement time scale, whereas the tunneling of hydrogen was too fast in AcAcH8 to be observed.

Table VI: Second group of conformers: experimental frequencies $\left(\mathrm{cm}^{-1}\right)$ in Ne compared to theoretical frequencies $\left(\mathrm{cm}^{-1}\right)$ [B3LYP/6-311++G(3df,3pd)]. Theoretical values in scaled harmonic approximation (and anharmonic approximation). Intensities $(\mathrm{km} / \mathrm{mol})$ obtained in the harmonic approximation.

\begin{tabular}{|c|c|c|c|c|c|c|}
\hline \multirow{2}{*}{ Assignments $^{a}$} & \multirow{2}{*}{ Experimental } & \multicolumn{4}{|c|}{ Theoretical } & \multirow{3}{*}{$\begin{array}{c}\text { Intensity } \\
56\end{array}$} \\
\hline & & \multicolumn{2}{|c|}{ TCC } & \multicolumn{2}{|c|}{ TCT } & \\
\hline$\checkmark O D$ & 2695.4 & & & 2737.3 & (2689.2) & \\
\hline$v O D$ & 2679.8 & 2714.8 & (2661.9) & & & 52 \\
\hline$v_{a}(C=C+C O)$ & 1681.8 & 1683.9 & $(1686.3)$ & & & 232 \\
\hline$v_{a}(C=C+C O)$ & 1678.0 & & & 1684.3 & $(1685.3)$ & 175 \\
\hline$v_{s}(C=C+C O)+\delta O D$ & 1664.1 & & & 1650.3 & (1646.3) & 363 \\
\hline$v_{s}(C=C+C O)+\delta O D$ & 1635.4 & 1617.2 & $(1614.0)$ & & & 397 \\
\hline$\delta_{\mathrm{a}} \mathrm{CH}_{3}(\mathrm{OD}$ side) & 1447.5 & 1451.2 & $(1451.2)$ & & & 36 \\
\hline$\delta_{\mathrm{a}} \mathrm{CH}_{3}(\mathrm{CO}$ side $)$ & 1427.2 & & & 1434.3 & $(1424.2)$ & 22 \\
\hline$\delta_{5} \mathrm{CH}_{3}(\mathrm{OD}$ side) & 1396.1 & 1394.2 & $(1407.8)$ & & & 33 \\
\hline$\delta_{5} \mathrm{CH}_{3}(\mathrm{OD}$ side) & 1389.2 & & & 1391.0 & $(1401.2)$ & 23 \\
\hline$\delta_{5} \mathrm{CH}_{3}(\mathrm{CO}$ side) & 1369.4 & & & 1367.7 & $(1360.3)$ & 48 \\
\hline$\delta_{5} \mathrm{CH}_{3}(\mathrm{CO}$ side) & 1354.1 & 1351.5 & $(1342.4)$ & & & 67 \\
\hline $\begin{array}{l}v(\text { carbon skeleton })+ \\
\delta_{5} \mathrm{CH}_{3}\end{array}$ & 1328.6 & 1328.0 & (1319.2) & & & 101 \\
\hline $\begin{array}{l}v(\text { carbon skeleton })+ \\
\delta_{5} \mathrm{CH}_{3}\end{array}$ & 1320.2 & & & 1314.3 & (1303.9) & 126 \\
\hline $\mathrm{v}_{\mathrm{s}} \mathrm{C}-\mathrm{CH}_{3}+\rho \mathrm{CH}_{3}$ (CO side) & 1224.1 & 1211.0 & $(1202.8)$ & & & 68 \\
\hline $\mathrm{v}_{\mathrm{s}} \mathrm{C}-\mathrm{CH}_{3}+\rho \mathrm{CH}_{3}$ (CO side) & 1222.6 & & & 1208.8 & $(1200.4)$ & 118 \\
\hline$\rho \mathrm{CH}_{3}(\mathrm{OD}$ side $)+\delta O D$ & 1098.0 & 1095.5 & (1093.3) & & & 41 \\
\hline$\rho \mathrm{CH}_{3}(\mathrm{OD}$ side $)+\delta O D$ & 1097.1 & & & 1093.8 & $(1092.3)$ & 36 \\
\hline $\mathrm{\rho CH}_{3}$ (CO side) & 1000.8 & & & 992.9 & $(993.2)$ & 44 \\
\hline $\mathrm{\rho CH}_{3}$ (OD side) & 994.1 & 991.7 & (990.3) & & & 55 \\
\hline $\mathrm{\rho CH}_{3}$ (CO side) & 977.0 & 970.9 & (970.3) & & & 18 \\
\hline$\delta C D+\delta O D$ & 936.2 & 921.3 & (903.8) & & & 40 \\
\hline$\delta O D$ & 919.0 & & & 903.5 & (908.7) & 25 \\
\hline$\delta \mathrm{CD}$ & 847.6 & & & 845.2 & (853.1) & 47 \\
\hline
\end{tabular}

${ }^{a}$ main characteristic motions; $\mathbf{v}$, stretching; $\boldsymbol{\delta}$, in plane bending; $\boldsymbol{\rho}$, in plane rocking; $\boldsymbol{\Delta}$, in plane ring deformation; s, symmetric; a, asymmetric 
In the present experiments, there is no evidence of the TTC conformer which was detected in a very low amount in $\mathrm{AcAcH} 8 / \mathrm{Ne}$. As the bands were very weak, if TTC(D2) exists, its bands cannot be clearly distinguished from bands coming from the different conformers of AcAcD1. So, no conclusion can be stated for TTC(D2).

In addition to the experiments previously discussed, we performed a supplementary irradiation at $250 \mathrm{~nm}$ after the irradiation at $260 \mathrm{~nm}$ in order to excite more efficiently the second group itself. This last irradiation induces a change inside the second group: TCT bands increase and TCC bands decrease. We do not see any increase of the bands associated with other conformers. It suggests that the TCT/TCC production ratio depends on the energy of the system in the excited $S_{2}$ state and/or on the initial geometry of acetylacetone in this state. Consequently, the measured TCT/TCC ratio in Ne depends on the UV irradiation wavelength just after UV irradiation and then evolves in time. Because of the fast TCT $\rightarrow$ TCC conversion in the case of $\mathrm{AcAcH} 8$, this kind of process cannot be explored with the fully hydrogenated isotopologue. On the other hand, TCT was also observed in more perturbative matrices ( $\mathrm{Ar}, \mathrm{Xe}, \mathrm{N}_{2}, n-\mathrm{H}_{2}$ and $n-\mathrm{D}_{2}$ ) where it can be stabilized by interactions with the host. In these latter cases, matrix effects must play a role in the observed molecular processes.

\section{3. $d$. Monodeuterated conformers}

The assignment of AcACD1 open conformers is very difficult, due first to their low concentration compared to AcAcD2 conformers, and second to the mixture of $A C A C D 1(C D)$ and $A c A c D 1(O D)$ conformers. Nevertheless, we assign several bands to the first group of AcAcD1(OD) isotopologue (CTT: 904.5, 1155.7, 1361.0, $1395.2 \mathrm{~cm}^{-1}$; CTC: $989.3,1038.1,1165.2,1412.9 \mathrm{~cm}^{-1}$ ) and only one to ACACD1(CD) isotopologue (CTC: $1181.0 \mathrm{~cm}^{-1}$ ). In the second group we were also able to assign some bands of ACACD1(OD) isotopologue (TCT: 899.6, 998.0, 1192.7, $1263.1 \mathrm{~cm}^{-1}$; TCC: $974.8,989.2,1264.1,1365.7 \mathrm{~cm}^{-1}$ ). Most of the ACACD1(OD) bands are assigned thanks to interconversion by IR irradiation, taking into account that the OD stretching modes in AcAcD2 and $A C A C D 1(O D)$ have very similar frequencies (see ESI for theoretical values). Other bands are observed but a straightforward assignment is not possible.

\section{3. e. Tunneling process}


$\mathrm{CTT} \rightarrow \mathrm{CTC}$ and TCT $\rightarrow$ TCC interconversion processes are assumed to be due to proton tunneling because of the significant deuteration effect we observed. The tunnel effect is very important at low temperatures and it has been found in several small organic molecules and complexes. ${ }^{42,43}$ We performed relaxed scan (and Internal Reaction Coordinate) calculations in order to estimate the rotational barriers for the processes under study. The theoretical heights of the barriers, ZPE included, for both pairs of conformers and both isotopologues (AcAcH8 and AcAcD2) are reported in Table VII. $\triangle$ ZPE is the difference in ZPE energies obtained for the transition state and the trans conformer XYT (CTT or TCT); $\omega_{0}$ is the calculated $\mathrm{OH} / \mathrm{OD}$ rotation frequency $\left(\gamma_{\mathrm{OH}}\right.$ mode) at MP2 level.

A first conclusion is that these barriers are too high compared to thermal energy $\left(6.7 \times 10^{-2} \mathrm{~kJ} / \mathrm{mol}\right.$ at $8 \mathrm{~K}$ ) to be overpassed thermally, confirming the tunneling assumption. As indicated by the values reported in Table VII, the differences in rotational barrier heights between both isotopologues are small, confirming also that the different heights do not govern the different behaviors of $A c A c D 2$ and $A c A c H 8$. The two barriers (IRC calculation) are drawn in Fig. 10 in the case of double deuterated isotopologues. They are found very similar (height and width), the barrier is slightly lower between TCT and TCC than between CTT and CTC.

Table VII: Theoretical rotational barrier (in $\mathrm{kJ} / \mathrm{mol}$ and $\mathrm{cm}^{-1}$ ), ZPE difference ( $\triangle \mathrm{ZPE}$ in $\mathrm{kJ} / \mathrm{mol}$ ) and frequency of the $\mathrm{OH} / \mathrm{OD}$ rotational mode $(\mathrm{Hz})$ at MP2 level for the pairs of observed conformers, experimental and calculated tunneling rates, $k\left(\mathrm{~s}^{-1}\right)$.

\begin{tabular}{|c|c|c|c|c|}
\hline & \multicolumn{2}{|c|}{$\mathrm{CTT} \rightarrow \mathrm{CTC}$} & \multicolumn{2}{|c|}{ TCT $\rightarrow$ TCC } \\
\hline & AcAcH8 & AcAcD2 & AcAcH8 & AcAcD2 \\
\hline $\begin{array}{r}\text { Barrier height }\left(\mathbf{k J} / \mathrm{mol}^{\ddagger}\right. \\
{\left[\mathrm{cm}^{-1}\right]}\end{array}$ & $\begin{array}{c}23.8 \\
{[1989.5]}\end{array}$ & $\begin{array}{c}24.5 \\
{[2048.0]}\end{array}$ & $\begin{array}{c}21.4 \\
{[1788.9]}\end{array}$ & $\begin{array}{c}22.1 \\
{[1847.4]}\end{array}$ \\
\hline (kJ/mol) & 2.8 & 2.1 & 2.5 & 1.8 \\
\hline \multirow[t]{2}{*}{$(\mathrm{Hz})$} & $1.17 \times 10^{13}$ & $8.69 \times 10^{12}$ & $1.09 \times 10^{13}$ & $8.29 \times 10^{12}$ \\
\hline & \multicolumn{4}{|c|}{ Tunneling rate constant $(k)$} \\
\hline Experimental value & - & $5 \times 10^{-7}$ & - & $3 \times 10^{-6}$ \\
\hline Theoretical value & $2 \times 10^{-1}$ & $2 \times 10^{-7}$ & 1 & $3 \times 10^{-6}$ \\
\hline
\end{tabular}

₹ ZPE included 


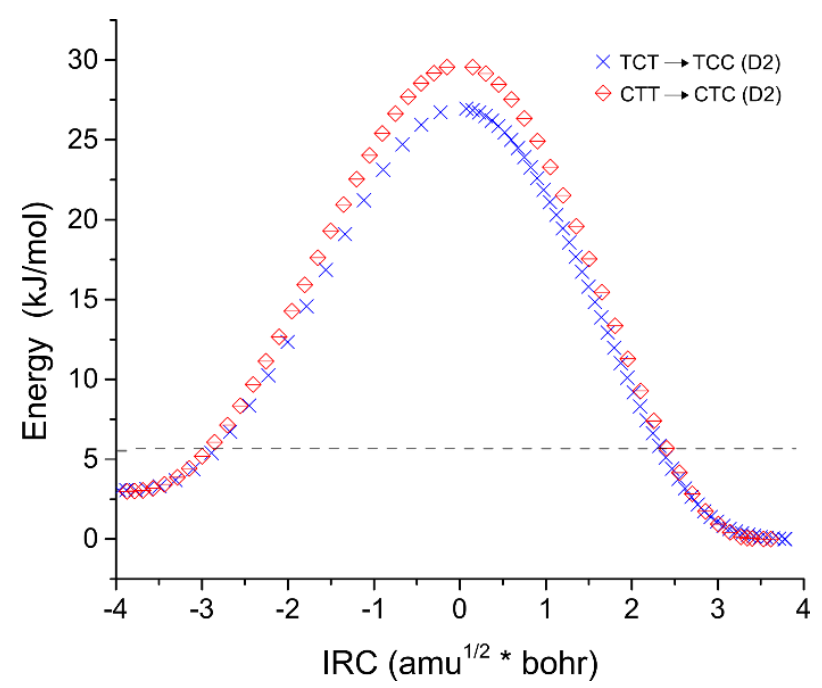

Figure 10: Calculated CTT $\rightarrow$ CTC and TCT $\rightarrow$ TCC (from the left to the right) theoretical barriers, through IRC method. The dashed line represents approximately the kinetic energy of the particle (deuterium atom), estimated as $\triangle Z P E=Z P E$ (trans) $-Z P E(T S)$ (different for each pair -see Table VII).

The experimental kinetic constants $k$ related to the tunneling rates are estimated for each pair from the evolution after $68 \mathrm{~h}$ of the intensities of some characteristic bands assigned to each conformer. We can compare them with the theoretical values obtained within the WKB semiclassical approximation. ${ }^{44}$ This methodology has been successfully used in the description of other systems, but gives only an order of magnitude of the kinetic rate. ${ }^{45,46}$ In this approach, $k$ is expressed as:

$$
k_{W B K}=\omega_{0} \times P(\varepsilon)
$$

Where $\omega_{0}$ is the frequency of the torsional mode (in $\mathrm{Hz}$ ) and $P(\varepsilon)$ is the permeability of the barrier obtained through: ${ }^{44}$

$$
P(\varepsilon)=\frac{1}{1+e^{2 \theta(\varepsilon)}}
$$

with $\theta(\varepsilon)$ evaluated by the following integral:

$$
\theta(\varepsilon)=\frac{1}{\hbar} \int_{x_{1}}^{x_{2}} \sqrt{2 \mu[V(x)-\varepsilon]} d x
$$

where $\mu$ is the reduced mass of the particle and $\varepsilon$ its kinetic energy evaluated as the difference of the Zero Point Energies between the transition state (TS) and the initial state (XYT). Integration limits $x_{1}$ and $x_{2}$ are defined by the turning points where $V(x)-\varepsilon=0$.

The calculated values are reported in Table VII together with the estimated experimental values. A difference of six orders of magnitude in the values of the theoretical rates between non deuterated and deuterated isotopologues is found in each pair. The barriers are quite similar and the major difference comes from the reduced masses and $\triangle Z P E$ values in the two isotopologues. The orders of magnitude of $k$ obtained for the non-deuterated molecules 
highlight a fast tunneling process, in the timescale of seconds, and fully explain the absence of XYT(H8) conformers in the FT-IR spectra recorded more than few seconds after the laser irradiation. ${ }^{14}$ Deuteration totally changes the XYT lifetimes. Theoretical values for deuterated pairs describe very well the slow process observed. We obtain a very good agreement for both pairs of conformers, despite the WKB approximation and the fact that the matrix is not taken into account. It seems that the effect of the neon matrix in this process is negligible. Generally, the presence of the matrix slows down the isomerization, but it depends both on the host and the guest. ${ }^{45,47}$ Theoretical estimations open in fact a puzzling matrix effect: whereas tunneling rate constants are larger for TCT $\rightarrow$ TCC than for CTT $\rightarrow C T C$, TCT is found easier stabilized by a cryogenic lattice than CTT (TCT is observed in Ar, $n-\mathrm{H} 2$ and $n-\mathrm{D} 2$ and not CTT). This could be related to the fact that in the TCT/TCC pair, the $\mathrm{OH}$ group stays in the vicinity of methyl groups, while it is only the case in the less stable CTT conformer of the CTT/CTC pair (see Fig. 2): the geometries of two methyl groups are slightly modified in the TCT $\rightarrow$ TCC process, while only one is involved in the CTT $\rightarrow$ CTC tunneling and the global modification of the molecule can be more perturbed by the matrix in the former case than in the latter.

\section{Conclusions}

Deuteration effects on the molecular properties of acetylacetone are explored by the study of the double deuterated acetylacetone (AcAcD2) trapped in neon matrices with a focus on vibrational spectroscopy and photochemistry.

The IR spectrum of the chelated enol form exhibits well-defined and narrow bands. It allows the assignment of most of the vibrational modes, whereas the previous spectroscopic data were obtained in the gas phase at room temperature and many bands were thermally broadened. The agreement with the gas phase and the theoretical calculations is very good, underlining the weakness of the perturbation induced by the neon environment. The IR spectra of the monodeuterated isotopologues are also obtained.

The comparison between the spectroscopic results of $A c A c H 8, A c A c D 2$ and AcAcD1 trapped in solid neon highlights the effect of the strong internal hydrogen bond in the $-\mathrm{OH}$ isotopologues: almost all the vibrational bands are broadened, and not only those which are the most involved in the $\mathrm{H}$-bond. Because of the narrowing of bands in AcAcD2, we were able to detect its OD 
stretching mode around $2000 \mathrm{~cm}^{-1}$ whereas the corresponding $\mathrm{OH}$ stretching mode was always too large to be detected.

Excitation of AcAcD2 to $S_{2}$ state induces the isomerization of the enol form in solid neon. As for $\mathrm{AcAcH} 8$, we distinguish two groups of conformers in the photo-isomerization process. Nevertheless, there are two major differences. The first is the number of conformers. We observed the CTT/CTC and the TCT/TCC pairs. Only the corresponding XYC conformers were detected in $\mathrm{AcAcH} 8 / \mathrm{Ne}$ samples $^{14}$, suggesting that in $\mathrm{AcAcH} 8$ the XYT conformers disappeared as soon as they are produced by an efficient XYT $\rightarrow$ XYC interconversion. The second difference, related to the first one, is the slow XYT $\rightarrow \mathrm{XYC}$ interconversion observed when $\mathrm{AcAcD} 2 / \mathrm{Ne}$ samples stay in the dark. The slowing down of this process with deuteration is in agreement with the assumption of a quantum tunneling in the $-\mathrm{OH}(\mathrm{D})$ part of the molecule and the measured lifetimes are in very good agreement with calculations. These measurements also underline the weak interaction between the guest and the Ne matrix for this process.

Additional laser irradiation of the open enol conformers in the first overtones of their OD stretching modes induces reversible $\mathrm{XYT} \leftrightarrow \mathrm{XYC}$ interconversion. This process occurs in the ground state, similarly to the tunneling process. It allows a clear assignment of the IR spectra of the observed open conformers and the experimental measurement of the overtones frequencies.

The study will be extended to other deuterated isotopologues in order to get a deeper insight on the deuteration effect and, in particular, to analyze the consequences of the deuteration of the methyl groups whose torsion is entangled with the proton transfer in the chelated enol conformer. ${ }^{48}$ Similar studies in halogenated analogs of acetylacetone are also under way.

\section{Acknowledgements}

This work was supported by the RTRA Triangle de la Physique (2010-004-T NOSTADYNE and 2013-0436T REACMAQ). The authors are grateful to Dr. Justinas Ceponkus for fruitful discussions.

\section{References}

1. K. Hinsen and B. Roux, J. Chem. Phys., 1997, 106, 3567-3577.

2. I. Matanović, N. Došlić, and Z. Mihalić, Chem. Phys., 2004, 306, 201-207.

3. J. Mavri and J. Grdadolnik, J. Phys. Chem. A, 2001, 105, 2045-2051. 
4. F. Dolati, S. F. Tayyari, M. Vakili, and Y. A. Wang, Phys. Chem. Chem. Phys., 2016, 18, 344-350.

5. M. M. Folkendt, B. E. Weiss-Lopez, J. P. Chauvel, and N. S. True, J. Phys. Chem., 1985, 89, 3347-3352.

6. M. Temprado, M. V. Roux, P. Umnahanant, H. Zhao, and J. S. Chickos, J. Phys. Chem. B, 2005, 109, 12590-12595.

7. N. V. Belova, V. V. Sliznev, H. Oberhammer, and G. V. Girichev, J. Mol. Struct., 2010, 978, 282-293.

8. R. R. Lozada-García, J. Ceponkus, W. Chin, M. Chevalier, and C. Crépin, Chem. Phys. Lett., 2011, 504, 142-147.

9. P. Roubin, T. Chiavassa, P. Verlaque, L. Pizzala, and H. Bodot, Chem. Phys. Lett., 1990, 175, 655-659.

10. N. Nagashima, S. Kudoh, M. Takayanagi, and M. Nakata, J. Phys. Chem. A, 2001, 105, 10832-10838.

11. X. B. Chen, W. H. Fang, and D. L. Phillips, J. Phys. Chem. A, 2006, 110, 4434-4441.

12. A. Trivella, T. N. Wassermann, J. M. Mestdagh, C. Manca Tanner, F. Marinelli, P. Roubin, and S. Coussan, Phys Chem Chem Phys, 2010, 12, 8300-8310.

13. P. K. Verma, F. Koch, A. Steinbacher, P. Nuernberger, and T. Brixner, J. Am. Chem. Soc., 2014, 136, 14981-14989.

14. R. R. Lozada-García, J. Ceponkus, M. Chevalier, W. Chin, J.-M. Mestdagh, and C. Crépin, Phys. Chem. Chem. Phys., 2012, 14, 3450-3459.

15. R. J. Irving and I. Wadsö, Acta Chem. Scand., 1970, 24, 589-592.

16. J. N. Spencer, E. S. Holmboe, M. R. Kirshenbaum, D. W. Firth, and P. B. Pinto, Can. J. Chem., 1982, 60, 1178-1182.

17. W. Caminati and J. U. Grabow, J. Am. Chem. Soc., 2006, 128, 854-857.

18. R. Srinivasan, J. S. Feenstra, S. T. Park, S. Xu, and A. H. Zewail, J. Am. Chem. Soc., 2004, 126, 2266-2267.

19. S. A. Broadbent, L. A. Burns, C. Chatterjee, and P. H. Vaccaro, Chem. Phys. Lett., 2007, 434, 31-37.

20. I. Matanović and N. Došlić, J. Phys. Chem. A, 2005, 109, 4185-4194.

21. A. Trivella, S. Coussan, T. Chiavassa, P. Theule, P. Roubin, and C. Manca, Low Temp. Phys., 2006, 32, 1042-1049.

22. S. Coussan, C. Manca, Y. Ferro, and P. Roubin, Chem. Phys. Lett., 2003, 370, 118-125.

23. A. Trivella, P. Roubin, P. Theulé, M. Rajzmann, S. Coussan, and C. Manca, J. Phys. Chem. A, 2007, 111, 3074-3081.

24. H. P. Upadhyaya, A. Kumar, and P. D. Naik, J. Chem. Phys., 2003, 118, 2590-2598.

25. S. Xu, S. T. Park, J. S. Feenstra, R. Srinivasan, and A. H. Zewail, J. Phys. Chem. A, 2004, 108, 6650-6655.

26. L. Poisson, P. Roubin, S. Coussan, B. Soep, and J. M. Mestdagh, J. Am. Chem. Soc., 2008, 130, 2974-2983. 
27. L. Khriachtchev, J. Mol. Struct., 2008, 880, 14-22.

28. K. Marushkevich, L. Khriachtchev, J. Lundell, A. V. Domanskaya, and M. Räsänen, J. Mol. Spectrosc., 2010, 259, 105-110.

29. H. Ogoshi and K. Nakamoto, J. Chem. Phys., 1966, 45, 3113-3120.

30. S. F. Tayyari, T. Zeegers-Huyskens, and J. L. Wood, Spectrochim. Acta A, 1979, 35, 12651276.

31. S. F. Tayyari, T. Th. Zeegers-Huyskens, and J. L. Wood, Spectrochim. Acta A, 1979, 35, 1289-1295.

32. S. F. Tayyari and F. Milani-nejad, Spectrochim. Acta Part a-Molecular Biomol. Spectrosc., 2000, 56, 2679-2691.

33. P. Kin-Kin Dea, California Institute of Technology, 1972.

34. A. D. Becke, J. Chem. Phys., 1996, 104, 1040-1046.

35. C. Lee, W. Yang, and R. G. Parr, Phys. Rev. B, 1988, 37, 785-789.

36. M. J. Frisch, G. W. Trucks, H. B. Schlegel, G. E. Scuseria, M. A. Robb, J. R. Cheeseman, G. Scalmani, V. Barone, B. Mennucci, G. A. Petersson, H. Nakatsuji, M. Caricato, X. Li, H. H. P., A. F. Izmaylov, J. Bloino, G. Zheng, D. J. Sonnenb, M. Hada, M. Ehara, K. Toyota, R. Fukuda, J. Hasegawa, M. Ishida, T. Nakajima, Y. Honda, O. Kitao, H. Nakai, T. Vreven, J. Montgomery, J. A., J. E. Peralta, F. Ogliaro, M. Bearpark, J. J. Heyd, E. Brothers, K. N. Kudin, V. N. Staroverov, R. Kobayashi, J. Normand, K. Raghavachari, A. Rendell, J. C. Burant, S. S. Iyengar, J. Tomasi, M. Cossi, N. Rega, J. M. Millam, M. Klene, J. E. Knox, J. B. Cross, V. Bakken, C. Adamo, J. Jaramillo, R. Gomperts, R. E. Stratmann, O. Yazyev, A. J. Austin, R. Cammi, C. Pomelli, J. W. Ochterski, R. L. Martin, K. Morokuma, V. G. Zakrzewski, G. A. Voth, P. Salvador, J. J. Dannenberg, S. Dapprich, A. D. Daniels, O. Farkas, J. B. Foresman, J. V Ortiz, J. Cioslowski, and D. J. Fox, Gaussian 09, Revision D.01, Gaussian, Inc., Wallingford CT., 2009.

37. http://www.chemcraftprog.com.

38. D. L. Howard, H. G. Kjaergaard, J. Huang, and M. Meuwly, J. Phys. Chem. A, 2015, 119, 7980-7990.

39. Z. Mielke and L. Sobczyk, in Isotope Effects In Chemistry and Biology, eds. A. Kohen and H. H. Limbach, Taylor \& Francis, CRC Press, Boca Raton, 2005, pp. 281-304.

40. S. Coussan, Y. Ferro, A. Trivella, M. Rajzmann, P. Roubin, R. Wieczorek, C. Manca, P. Piecuch, K. Kowalski, M. Wloch, S. A. Kucharski, and M. Musial, J. Phys. Chem. A, 2006, 110, 3920-3926.

41. H. Nakanishi, H. Morita, and S. Nagakura, Bull. Chem. Soc. Jpn., 1977, 50, 2255-2261.

42. E. M. S. Maçôas, L. Khriachtchev, M. Pettersson, R. Fausto, and M. Räsänen, Phys. Chem. Chem. Phys., 2005, 7, 743-749.

43. M. Tsuge, K. Marushkevich, M. Räsänen, and L. Khriachtchev, J. Phys. Chem. A, 2012, 116, 5305-5311.

44. R. P. Bell, The Tunnel Effect in Chemistry, Springer US, Boston, MA, 1980.

45. M. Tsuge and L. Khriachtchev, J. Phys. Chem. A, 2014, 119, 2628-2635.

46. A. Olbert-Majkut, J. Ahokas, M. Pettersson, and J. Lundell, J. Phys. Chem. A, 2013, 117, 
1492-1502.

47. A. Domanskaya, K. Marushkevich, L. Khriachtchev, and M. Räsänen, J. Chem. Phys., 2009, 130, 154509.

48. R. R. Lozada-García, J. Ceponkus, M. Chevalier, W. Chin, J. M. Mestdagh, and C. Crépin, Angew. Chemie - Int. Ed., 2012, 51, 6947-6950. 